\title{
Advance Requests for Medically-Assisted Dying
}

\author{
L.W. Sumner \\ sumner@chass.utoronto.ca
}

When Medical Assistance in Dying (MAiD) was legalized in Canada in June 2016, three issues were reserved for further consideration during the mandatory parliamentary review originally scheduled to begin in June 2020 (but since delayed by COVID-19): requests for MAiD by mature minors, requests by patients for whom mental illness is the sole underlying medical condition, and advance requests in anticipation of incapacity. ${ }^{1}$ Action on each of these issues could result in expansion of the current eligibility criteria for MAiD. I am concerned here only with the last of them, which I regard as the most complex and difficult.

There are two topics I will not be discussing: whether MAiD can, under appropriate conditions, be ethically justified and whether it should, under these conditions, be legally available. I have dealt with both of these questions at length elsewhere and do not plan to reopen them here. ${ }^{2}$ In Canada legal access to MAiD is here to stay and enjoys widespread public support; any future changes in the law will almost certainly be in the direction of expanding its eligibility criteria or loosening its procedural safeguards. One of those potential expansions is to allow MAiD to be accessed by means of a request made in advance of loss of decision-making capacity.

In its current form the MAiD legislation does not permit such requests, since it stipulates that at the time at which the procedure is to be administered the patient must give "express consent" to receiving it. ${ }^{3}$ Since express consent presupposes decisional capacity, this requirement rules out administering MAiD to a patient who has lost capacity. Pursuant to the

\footnotetext{
${ }^{1}$ Bill C-14, An Act to amend the Criminal Code and to make related amendments to other Acts (medical assistance in dying), SC 2016, s. 10 (1)(2).

${ }^{2}$ Sumner 2011.

${ }^{3}$ C-14, s. $241.2(3)(\mathrm{h})$.
} 
legislation, in December 2016 the government commissioned a report by the Council of Canadian Academies whose purpose was to summarize the evidence and issues concerning advance requests for MAiD, but not to make any recommendations. That report was submitted in December 2018. ${ }^{4}$ Amendments to the legislation (Bill C-7), passed by Parliament in March 2021, have opened the door slightly by allowing advance requests by patients after they have been approved for MAiD, if they fear losing capacity before the procedure can be administered. ${ }^{5}$ But this provision applies only to patients whose natural death is deemed to be "reasonably foreseeable", and continues to exclude (a) requests made after diagnosis of a "grievous and irremediable medical condition" but in advance of approval for MAiD, and (b) requests made before such a diagnosis.

My aim here is twofold: to explore the ethical and legal issues concerning advance requests for $\mathrm{MAiD}$, and to argue for expanding provision for such requests to include both of these further scenarios. However, I will work toward these goals incrementally, beginning with some needed groundwork. What follows in the next three sections is not intended to be in any way original or innovative. It will be familiar territory for many readers, but is worth traversing because it is highly relevant to the further, and more contested, issues of advance directives and advance MAiD requests.

\section{The Doctrine of Informed Consent}

It is now a firmly established legal and ethical principle that a competent person cannot be subjected to medical treatment without their informed consent. ${ }^{6}$ The classical doctrine includes four conditions for valid consent to treatment. ${ }^{7}$

\footnotetext{
${ }^{4}$ Expert Panel Working Group on Advance Requests for MAiD 2018.

${ }^{5}$ Bill C-7, An Act to amend the Criminal Code and to make related amendments to other Acts (medical assistance in dying), SC 2021. https://parl.ca/DocumentViewer/en/43-2/bill/C-7/royal-assent.

${ }^{6} \mathrm{~A}$ standard treatment of informed consent can be found in Faden and Beauchamp 1986. For its application in Canadian law, see Gilmour 2017.

${ }^{7}$ Expert Panel Working Group on Advance Requests for MAiD 2018, 30-2.
} 
Decisional capacity. Competence, or decisional capacity, is basically the ability to make a reasoned decision whether to accept or reject a particular form of treatment. At the minimum it includes the ability to understand and appreciate the nature and consequences of both agreeing to and declining a treatment option. ${ }^{8}$ Decisional capacity is the default presumption for adult patients. However, the presumption is rebuttable by evidence of a mental illness or disability serious enough to impair cognitive functioning. Young children, on the other hand, will generally be presumed to be decisionally incapable, though there will of course be a grey area located somewhere during adolescence (so-called 'mature minors'). It is important to note that the relevant decisional capacity for informed consent is treatment-specific: it is the ability to make a reasoned decision concerning this treatment at this time by this practitioner. A person may be competent to make other personal decisions (such as financial ones) but not treatment decisions, may be competent to make some treatment decisions but not others, and may be competent to make particular treatment decisions at some times and not others.

Consent. Consent is likewise treatment-specific. In some contexts, such as normal medical procedures during a routine checkup, tacit consent may be inferred from the mere fact that the patient has turned up for their appointment and is registering no objection to the examination. For more serious procedures, explicit consent will be necessary, preferably by means of a written consent form.

Voluntariness. The patient's giving of consent must be free of undue influence and coercion, whether by providers or by family or friends. It is recognized, of course, that our decisionmaking as patients will often be influenced by what others think or suggest or by our knowledge of what they want or would prefer. Since it would aim much too high to purge decision-making of all such influences, the issue of voluntariness will turn on when such influences are 'undue'that is, when they rise to the level of force, deceit, duress, or some other form of manipulation or

\footnotetext{
${ }^{8}$ For a more detailed list of the components of decisional capacity, see Appelbaum 2007, 1236.
} 
coercion. As with decisional capacity, there will inevitably be borderline cases in which the voluntariness of patient consent to treatment is uncertain.

Information. The patient must be provided with adequate information concerning the treatment option in question. This information will normally include the patient's diagnosis, prognosis in the absence of treatment, the nature of each of the available treatment options, the probable outcome of each option, and the risks attached to each option. The general rule for disclosure is that it should include all of the information which a reasonable person in this particular patient's circumstances would need in order to make a reasoned decision concerning the treatment in question.

\section{Informed Refusal of Treatment}

"The logical corollary of this doctrine of informed consent is that the patient generally has the right not to consent, that is the right to refuse treatment and to ask that it cease where it has already been begun." In fact, the relationship between consent and refusal is even closer than this talk of a 'corollary' suggests. If consent is necessary for being treated, then, logically, absence of consent is sufficient for not being treated. Since refusing treatment is the most emphatic way of withholding consent, the right of treatment refusal is an inextricable part of the doctrine of informed consent. ${ }^{10}$ While much medical treatment is routine, some is not. At the extreme, where initiation or continuation of treatment is necessary in order to sustain life, refusal of treatment can become life-threatening. Even in these cases, however, there is no real ethical or legal issue about the patient's right of refusal. It is well established in both ethics and law that even when the stakes are this high refusal of treatment by a decisionally capable patient must be respected. ${ }^{11}$

\footnotetext{
${ }^{9}$ Nancy B v. Hôtel-Dieu de Québec et al., (1992) 86 DLR (4th) 385, at 390 [henceforth: Nancy B.].

${ }^{10}$ Whether the conditions for valid refusal are the same as those for valid consent will be considered later (sections $11 \& 12$ ).

${ }^{11}$ Carter v. Canada (Attorney General), 2012 BCSC 886 [henceforth Carter 2012], at para 220: "Since Rodriguez, the common law principles relating to competent adult patients have been clear. Individual autonomy gives competent, informed patients the right to consent to treatment, including the right to
} 


\section{The Goals of Informed Consent}

Though the doctrine of informed consent (and refusal) is well established in both ethics and law, it is still appropriate to ask which goals or values it is meant to serve. There are two obvious answers to this question —one, perhaps, more obvious than the other.

Patient autonomy. Since the doctrine puts the patient in charge of determining what may be done with their body, it obviously serves the value of autonomy. ${ }^{12}$ As I shall understand it, exercising autonomy (or self-determination) is a matter of managing one's own life in accordance with one's own values and priorities. The concept of autonomy has received a great deal of attention (arguably too much attention) in recent decades, resulting in a bewildering array of competing analyses, many of which have little or nothing to do with the decision-making context of informed consent. The more robust conceptions of autonomy can require sophisticated capacities - for rational determination of the will or a high level of critical selfreflection - which no informed consent protocol demands. Under these interpretations most of us probably fail to be autonomous most of the time, and this will include patients making decisions about medical treatment. We can, with greater expectation of success, aim to ensure that these decisions are made in accordance with our own life goals and values. For the purposes of this discussion, that will suffice for being autonomous.

Autonomy therefore requires being the one who makes the major decisions about how their life is to go: what educational and career path to pursue, where to live, whether and whom to marry, whether to have children, how to spend leisure time, what social/political causes to support, and so on. The presumptive point of the requirement of informed consent is to provide us with the same managerial opportunity with respect to our health care. While many treatment decisions will be relatively trivial, some will have a profound impact on the course of our lives. In theory at least, the regime of informed consent is meant to ensure that no treatment goes

withdraw consent to life-sustaining treatment." This statement was affirmed by the Supreme Court: Carter v. Canada (Attorney General), 2015 SCC 5 [henceforth Carter 2015], at para 67. The Nancy B case, cited above, concerned the withdrawal of life-sustaining treatment (a mechanical ventilator).

${ }^{12}$ Expert Panel Working Group on Advance Requests for MAiD 2018, 48-50. 
forward unless or until we have signed off on it. No one else gets to make that final decision, no one else gets to determine how our therapeutic process will go-only we do.

Patient interest. While self-determination may be valuable in its own right-most of us want to be masters of our fate and captains of our soul — it is also an effective means whereby we are enabled to pursue our own best interest. A decisionally capable and well-informed agent is normally in a better position to act in their best interest than is any third party. Giving the agent final authority over their health-care decisions will then be an effective way of ensuring that those decisions are guided by their own interest and not by anyone else's.

Patient autonomy and patient interest will normally run together as the two justifying values of the doctrine of informed consent. Normally, but not necessarily. Free and fully informed self-determiners who surpass the threshold of decisional capacity are nonetheless capable of making decisions to their own detriment. Devout Jehovah's Witnesses, for example, may decline blood transfusions even when they are necessary to sustain life. In cases like this the twin justifying values of the doctrine may come apart: respecting autonomy will require acquiescence in the patient's decision while promoting patient interest may urge disregarding it. When this happens the doctrine tends to side with autonomy against interest: as long as the patient in question is decisionally capable, fully informed, and free of the undue influence of others then in the absence of consent no treatment may be administered, whatever the adverse impact of nontreatment might be.

\section{Advance Directives}

The doctrine of informed consent (and refusal) applies in the first instance to decisions that are contemporaneous with the treatment in question. But decisions by capable individuals can also be made in advance. Should you lose capacity at some stage of your life and require medical attention, you will not at that time be able to manage your own treatment decisions. Someone else will have to decide for you, in light either of (what they take to be) your wishes or (what they take to be) your best interest. However, at an earlier stage of life, when you are still 
capable, you may anticipate that you might later find yourself in this condition. If you wish to be able to exercise some degree of control over your later treatment then the obvious mechanism is to register your treatment decisions in advance, ideally in a written instrument. These will be now-for-then decisions, as opposed to the normal contemporaneous now-for-now decisions. But because they are made by a decisionally capable person, though applicable only in the event of incapacity, they will still count as the exercise of (diachronic rather than synchronic) autonomy or self-determination.

There are two types of instrument available for advance care planning. ${ }^{13}$ Instruction directives (also known as living wills) allow persons to stipulate which modes of treatment they accept, and which they reject, in various possible future scenarios. In effect, they provide the opportunity to register now the decisions the person would make then, if capable of doing so. These directives can, and often do, include decisions to accept or reject life-sustaining treatment in the event of a life-threatening condition. ${ }^{14}$ Proxy directives (also known as durable powers of attorney) appoint someone else to serve as substitute decision-maker (SDM) for the (later) incapacitated patient. Most advance directives include both types of instrument, in which case treatment decisions for the incapacitated patient are to be made by whomever the patient has designated in advance as their proxy, and they should be made on the basis of the patient's advance instructions. ${ }^{15}$

So understood, advance directives are a logical extension of the doctrine of informed consent and refusal. Just as the requirement of informed consent safeguards the individual's autonomy in contemporaneous treatment (or nontreatment) decisions, so the requirement that advance directives be respected safeguards the individual's autonomy over such decisions at later stages of their life. Furthermore, if we continue to assume that autonomous individuals are normally the best judges of their own interest, then respecting treatment (or nontreatment)

\footnotetext{
${ }^{13}$ Expert Panel Working Group on Advance Requests for MAiD 2018, 36-9.

${ }^{14}$ Henceforth, I will restrict attention to advance directives whose stipulations include refusal of (at least some forms of) life-sustaining treatment.

${ }^{15}$ Ibid., 45-7.
} 
decisions registered in advance will have the added justification that it is also protective of patient well-being. This model of advance care planning therefore appears to provide a straightforward means whereby formerly competent patients may exercise some degree of control over their end-of-life care. That control can take the form either of requesting or refusing familiar modes of treatment: resuscitation, tube feeding, ventilation, administration of antibiotics, sedation, and so on.

All of this seems straightforward. Sadly, it is not. Critics have raised a number of concerns about reliance on advance directives for decision-making on behalf of incapacitated patients. Some of these concerns turn on issues that are specific to one particular kind of incapacity — advanced dementia—and I will come to them later (section 7). But others are broader in scope, challenging the efficacy of advance care planning in general, and I will deal with them first.

Over the past four decades Rebecca Dresser has been the most persistent critic of advance directives. ${ }^{16}$ Most of her objections have been broadly practical in nature, pointing to various respects in which advance treatment decisions are less reliable than contemporaneous ones as expressions of patient self-determination. Although she does not sort them in this way, I will divide the issues she has raised into two categories: problems of information and problems of specificity.

The informational deficiencies of advance directives are best appreciated by contrasting them with contemporaneous care decisions, where the patient can (and must) be provided with all of the information a reasonable person in their circumstances would need in order to make a reasoned decision concerning the treatment in question. This process requires communication, preferably face to face, between the patient and their health care providers, with the attendant opportunity for both questioning and discussion. Furthermore, it must be emphasized again that the information is specific to this treatment for this condition and this patient. It can therefore be

\footnotetext{
${ }^{16}$ See, for instance, Dresser 1994; Dresser 2003.
} 
as full and detailed as the patient requires and the circumstances permit. In principle at least, contemporaneous decision-making can live up to the highest ideals of informed choice.

Contrast this rosy picture with treatment decisions made years, even decades, before the onset of incapacity and the need for treatment. Not only are there many types, and degrees, of incapacity, there are even more conditions for which an incapacitated patient might require lifesustaining treatment. To try to anticipate all of these future contingencies and make an informed treatment decision about each of them is a practical impossibility. Some possible scenarios can, of course, be discussed in advance as hypotheticals, but doing so is far less informative than a specific treatment consultation. Contemporaneous decision-making also has the advantage that the information provided is up to date. While it may not be possible to anticipate further discoveries or treatment modalities that would be relevant to the patient's decision, at least the current state of both knowledge and art can be fully communicated. By contrast, treatment decisions registered far in advance might be rendered obsolete or redundant by subsequent medical developments. Even if these decisions were as informed as possible then, they may not reflect the options available to the incapacitated patient now. For that reason they also may not reflect the informed choices the patient would make now, were they capable of such choices.

The informational deficiencies canvassed in the previous paragraph are all factual in nature. But it is equally possible for a person's values to shift with the passage of time, so that a decision autonomously made earlier in one's life ceases to have that status later. Advance directives can, of course, be modified, or revoked entirely, in response to changes of heart. But for various practical reasons this may not happen, with the result that the treatment decisions recorded in the written directive are now uninformed, not about factual matters, but about the subject's own preferences. Furthermore, it is often difficult, or even impossible, to anticipate in advance what it would be like to be in the various conditions for which one is trying to plan. As an active able-bodied person you might imagine full body paralysis, or 'locked-in' syndrome, to be unendurable. When it occurs you might discover that it still makes a meaningful life possible, 
but if you are unable to communicate treatment decisions at the time you might find yourself bound by your own earlier, uninformed, preferences.

The specificity problem for advance directives is a corollary of the foregoing informational impediments. Whereas contemporaneous consent or refusal is specific as to both treatment and occasion, advance instructions must attempt to anticipate a wide variety of treatment options and circumstances. While one might attempt to respond to each of these possible scenarios with detailed and precise directions concerning forms of treatment to be administered or withheld, there is a strong tendency toward broader and more general directions such as 'No resuscitation if I become terminally ill' or 'No life-sustaining measures whose burdens would outweigh their benefits'. Instructions as vague as these cannot be applied mechanically to later treatment decisions and therefore require interpretation both by SDMs and by providers. Indeed, instruction directives can be vaguer still, simply recording the subject's values or priorities for their life: 'I believe that life should have dignity' or 'I don't want to be too much of a burden on others'. In these cases advance directives lose much of their utility in determining treatment decisions for incapacitated patients.

Deficiencies of information and specificity can pose serious challenges to reliance on advance directives for decision-making on behalf of incapacitated patients, especially in end-oflife contexts. But these problems are not sufficient to entirely negate the value of such instruments. ${ }^{17}$ Even a vaguely worded directive provides some insight into a person's deeply held values and their goals for the end-stage of their life. If our aim is to respect a person's autonomy over their treatment decisions then a written directive must still be given serious weight. At the same time, the reasons for relying on a directive must also be rebuttable-by evidence that it was based on faulty or incomplete information or that the person's values have subsequently changed.

${ }^{17}$ For an influential critique of Dresser's views, see Rhoden 1990. 


\section{Advance Requests for MAiD}

As noted above, advance directives frequently take the form of selective refusal of various life-sustaining procedures, including in circumstances where such refusal will (probably or even certainly) have the effect of hastening death. However, they could also be used to request forms of end-of-life treatment, such as $\mathrm{MAiD}$, which will also have the effect of hastening death. From this point on, the argument of this paper will focus exclusively on advance requests for MAiD, under the following definition: "a request for MAiD, created in advance of a loss of decision-making capacity, intended to be acted upon under circumstances outlined in the request after the person has lost decisional capacity". ${ }^{18}$

I have argued elsewhere that, when all other relevant factors are equal, there is no significant ethical difference between refusing life-sustaining treatment and requesting MAiD. ${ }^{19}$ But that argument raises an important question: when are all other relevant factors equal?

Not always. MAiD has two key characteristics: (1) its administration will hasten death with certainty, and (2) it is requested for that reason, i.e. because the patient wishes to hasten their death. Not all refusals of life-sustaining treatment share the same characteristics. A cancer patient may decline further aggressive treatment, settling instead for palliative care, because the treatment has only a limited chance of long-term success and they find its side effects unbearable. Both the patient and their providers may expect the refusal to shorten life, but it may not turn out to do so: spontaneous remission may occur. More importantly, the treatment is not refused because the patient wishes to hasten death; if remission does occur, they will gratefully accept the further months or years of life. So we need to look elsewhere for instances in which all other relevant factors (besides the bare difference of request v. refusal) really are equal.

One such instance is the case of Nancy B., a twenty-five-year-old woman suffering from an irreversible neurological disorder that had left her incapable of movement and dependent on a

\footnotetext{
${ }^{18}$ Expert Panel Working Group on Advance Requests for MAiD 2018, 35.

${ }^{19}$ The argument for this ethical equivalence can be found in Sumner 2011, ch. 4. The equivalence was accepted by the trial judge in Carter 2012, at para 335 .
} 
ventilator. ${ }^{20}$ Her intellectual capacity was unaffected by the disease. After two and one-half years in this condition she requested removal of the respiratory support in order to escape the suffering caused by her immobility. With the ventilator she could potentially have lived on for several years; without it she would die quickly. While her decision was not opposed either by her health care providers or by the hospital, it was unclear whether under Canadian law disconnecting her from the ventilator would constitute criminal negligence causing death (a culpable homicide). Justice Dufour, who heard the case in the Quebec Superior Court, affirmed Nancy B.'s legal right to refuse continued use of the ventilator, even though such refusal would precipitate her death. Five weeks after the judgement, her attending physician induced Nancy B. into a coma and removed the ventilator; she died comfortably in her sleep. Nancy B.'s refusal of further use of the ventilator clearly hastened her death, ${ }^{21}$ and she refused it for that very reason. From an ethical standpoint there is no material difference between her refusing treatment, on the one hand, and requesting MAiD, on the other. ${ }^{22}$

Nancy B.'s decision to request removal of the ventilator was contemporaneous and not registered in an advance directive (though it is easy to imagine her executing such a directive to be acted on in the event of later incapacity). Furthermore, there does remain in her case the bare difference between actively causing her death (by MAiD) and allowing her to die of her illness (by removing the ventilator), and some might think that this 'doing/allowing' distinction itself makes an ethical difference even if all other relevant factors are equal. ${ }^{23}$ In that case, it is fortunate that we have on hand another end-of-life option that corrects for both of these deficiencies.

\footnotetext{
${ }^{20}$ See n. 9, above.

${ }^{21}$ The cause of death, however, was listed as her neurological disorder.

${ }^{22}$ The comparison is, of course, hypothetical since MAiD was not legally available in Canada at the time of her death in 1992. However, she would have qualified under the terms of the 2016 legislation.

${ }^{23}$ If so, they would be mistaken: Sumner 2011, 91-9.
} 
Voluntarily Stopping Eating and Drinking (VSED) is the decision by a capable patient to refuse all food and fluids, whether administered via a feeding tube or by mouth. ${ }^{24}$ A patient's right to refuse a feeding tube, or to demand its withdrawal, is beyond ethical or legal question, since the insertion of such a tube is a form of medical treatment. But patients have an equal right to decline food and fluids administered by mouth, even if this form of feeding constitutes basic or personal care rather than health care. ${ }^{25}$ To put the matter bluntly, patients may not be forcefed. VSED provides a legal means for patients to hasten their death, if MAiD is not available in their jurisdiction or if they do not qualify for it. Those who elect this route, and carry it through, will ultimately die of dehydration, usually in 7-10 days. In this case the final possible ethical difference from MAiD vanishes: like MAiD, VSED itself hastens death, rather than merely allowing it to happen, and, again like MAiD, it is chosen for this reason. VSED and MAiD are different routes to the same destination. ${ }^{26}$

When the patient is capable, then the decision to pursue VSED is contemporaneous (though capacity may be lost during the process). But the refusal of oral feeding can also be embedded in an advance directive (in which case this becomes Stopping Eating and Drinking by Advance Directive, or SED by AD). ${ }^{27}$ There are various forms of oral intake that can be restricted, or refused outright, in an advance directive, but for the purposes of this discussion I will assume that the person, while capable, has indicated refusal of all assisted feeding (by all second parties) under stipulated conditions of incapacity. SED by AD then becomes an analogue

\footnotetext{
${ }^{24}$ VSED has been discussed in the literature, as a legal means of hastening death, for quite some time: Bernat, Gert and Mogielnicki 1993; Terman 2007; Menzel 2017; Quill, et al. 2021.

${ }^{25}$ Bentley v. Maplewood Seniors Care Society 2014 BCSC 165, at para 46: “... there is common law authority for the proposition that it is necessary to obtain consent before providing personal care or basic care. Indeed, intentional non-consensual touching can amount to the tort of battery.... Although most cases relating to consent rights have been decided in the context of a right to consent or refuse consent for health care treatment, the principles on which that right is based is the general right to personal autonomy and bodily integrity." [Henceforth Bentley 2014] See also Downie 2018; Downie and Bowes 2019; Mader and Apold 2019 for the status of VSED, and SED by AD, under Canadian law.

${ }^{26}$ Where both are available, MAiD has many advantages over VSED: it relies much less on the willpower of the patient; it is completely free of discomfort; it is much less stressful for family, friends, and caregivers; and the timing of death is subject to much better control. But both are not always available.

${ }^{27}$ Menzel and Chandler-Cramer 2014; Quill, et al. 2021, Part II.
} 
of, and has the same ethical and legal authority as, an advance directive refusing life-sustaining medical treatment. Since there is no significant ethical difference between VSED and MAiD, there is also no difference between SED by $\mathrm{AD}$ and advance requests for MAiD. The reasons for respecting the former apply equally to the latter.

There is, therefore, a strong ethical case for permitting advance requests for MAiD. The argument thus far has taken the form of a plea for consistency: since we already accord ethical and legal authority to advance refusals of life-sustaining treatment (including SED by AD), it would be arbitrary to deny the same authority to advance MAiD requests. But advance requests can also be given a more positive and constructive justification by showing how they further serve the goals of informed consent, and of MAiD itself:

Patient autonomy. Like advance directives in general, advance MAiD requests enable persons, while capable, to extend their autonomy over their end-of-life treatment decisions to a possible future time of incapacity.

Patient interest. Like advance refusals of treatment, advance MAiD requests enable incapacitated persons to escape from living conditions which, while capable, they determined would be intolerable for them.

Preservation of life. Denying a patient in the early stages of a progressive degenerative illness such as Alzheimer's the option of an advance MAiD request, to be acted upon in the event of later incapacity, can have the perverse effect of leading them to seek MAiD, while still capable, sooner than they would otherwise wish, thereby foregoing some further weeks or months of quality of life. ${ }^{28}$ This consideration weighed heavily with the Supreme Court in its Carter decision striking down the previous laws prohibiting MAiD. ${ }^{29}$ It is just as much in play for this issue.

\footnotetext{
${ }^{28} \mathrm{Li}$, et al. 2017. One prominent example in Canada was Gillian Bennett: http://www.deadatnoon.com/. More broadly, see the "10 minutes to midnight" approach taken by some patients and providers: https://camapcanada.ca/wp-content/uploads/2019/05/Assessing-MAiD-in-Dementia-FINALFormatted.pdf.

${ }^{29}$ Carter 2015, at paras 57, 58.
} 
Peace of mind. Experience has already shown that patients approved for MAiD can benefit therapeutically just from the assurance that the option will be there for them when they need it. ${ }^{30}$ Having in place an advance request that they know will be acted on when needed can provide the same comfort. ${ }^{31}$

In light of the foregoing considerations, it is not surprising that the Provincial-Territorial Expert Advisory Group on Physician-Assisted Dying (2015) and the Special Joint Committee on Physician-Assisted Dying (2016) both recommended that the impending MAiD legislation allow for advance requests, ${ }^{32}$ nor that there is such strong public support now for amending the legislation to allow for such requests. ${ }^{33}$ It is even less surprising against the background of an aging population, where the prevalence of such conditions as Alzheimer's is expected to rise significantly over the next decade or so. ${ }^{34}$

Making the ethical case for permitting advance MAiD requests is the easy part. The harder task is to find workable solutions for the practical problems that will inevitably arise in accommodating them within the existing MAiD legislation. These problems are not simple and the best treatment of them is not always apparent. However, in the course of working through them, in the sections to follow, it will be useful to keep in mind that we have already encountered every one of them in connection with advance refusals of life-sustaining treatment in general, and SED by $A D$ in particular. Finding similar solutions for advance MAiD requests should not require us to reinvent the wheel.

\footnotetext{
${ }^{30}$ See, for instance, Li and Kain 2018.

${ }^{31}$ Expert Panel Working Group on Advance Requests for MAiD 2018, 140-1.

${ }^{32}$ Provincial-Territorial Advisory Group on Physician-Assisted Dying 2015, 31-2; Special Joint Committee on Physician-Assisted Dying 2016, 21-4.

${ }^{33}$ Expert Panel Working Group on Advance Requests for MAiD 2018, 41. See also the results of public consultations concerning MAiD conducted in January 2020: https://www.justice.gc.ca/eng/cj-jp/adam/wwh-cqnae/index.html.

${ }^{34}$ Expert Panel Working Group on Advance Requests for MAiD 2018, 39-41.
} 


\section{Loss of Capacity}

In principle, advance MAiD requests can anticipate a wide range of potential conditions of incapacity. But the most common condition, and the one most commonly anticipated in advance directives, is dementia. In addition to being a possible outcome of stroke or traumatic brain injury, this condition characterizes the end state of a number of diseases, including Huntington's and Parkinson's. But $60-70 \%$ of all dementia cases in Canada have a different cause: Alzheimer's disease. In what follows I will focus primarily on advance requests for MAiD that are executed in anticipation of late-stage Alzheimer's. This scenario can be adapted, where necessary, to fit the other circumstances resulting in severe dementia.

Alzheimer's is an incurable progressive neurodegenerative disorder that gradually erodes cognitive, executive, and motor functioning. ${ }^{35}$ The disease progression may be relatively rapid (over a year or so) or quite slow (over decades). Normal life expectancy following diagnosis is 3-9 years. The early symptoms are relatively mild, chiefly characterized by decreasing ability to retain newly learned information and by problems with language, including diminished vocabulary. As the disease progresses, patients will experience confusion or disorientation and gradually lose the ability to carry out tasks, to the point where they will eventually be unable to care for themselves or make simple decisions. In the later stages patients are likely to manifest psychiatric symptoms and behavioural disturbances, including mood swings, anxiety, fear, agitation, anger, outbursts of aggression, and paranoid delusions about family members, whom they are no longer able to recognize. Both language and motor skills will further deteriorate, to the point at which the patient will lose all ability to communicate and will be bedridden and incontinent. At this stage the patient is also likely to suffer due to pain, difficulty in breathing, agitation, ulcers, fever, and malnutrition. The immediate cause of death will often be infection or pneumonia. In the early stages patients will retain decisional capacity, but this capacity will

\footnotetext{
${ }^{35}$ Burns and Iliffe 2009. Alzheimer Society of Canada: https://alzheimer.ca/en/Home/Aboutdementia/Alzheimer-s-disease/Stages-of-Alzheimer-s-disease?gclid=CjwKCAjw7P1BRA2EiwAXoPWA60IguKh4MvEmebckMc9RZ6SCKUmx2n_j1tS6ohzUI4cPvoZJ0vRBoCCa0QAvD_BwE. Last accessed 11/05/20.
} 
gradually be lost over the course of the disease. Because the progression of symptoms is gradual, there will be no bright line between capacity and incapacity. But incapacity is the inevitable outcome.

Palliative measures are, of course, available for many of the distressing symptoms of latestage Alzheimer's. However, one study of these symptoms reached the following rather discouraging conclusion: ${ }^{36}$

A policy of deliberate euthanasia could be used to end suffering, but this is considered unacceptable by most caregivers and medical staff and is prohibited by law in most countries. A different approach is to encourage more aggressive palliative medical and nursing care to prevent malnutrition, decubitus ulcers, infections, and other disorders which can be treated in special units for patients with higher levels of suffering. We believe that lower levels of suffering in end-stage dementia patients can be achieved, at least in part, by better medical and nursing treatment. This still needs to be proven by further research, because it is not clear to what extent suffering can be eased and whether this is possible at all.

The same study found that $63 \%$ of end-stage dementia patients die with "a high level of suffering" and only $7 \%$ with a low level.

By any reasonable measure, then, Alzheimer's is a terrible disease and, ultimately, a terrible way to die. It is easy to understand, therefore, why someone diagnosed with the disease would want to take steps to avoid its later ravages while still competent to do so. It is equally easy to understand why someone might want to take similar steps in advance of diagnosis, especially if they have reason to believe - perhaps in light of family history — that they are particularly at risk of it. ${ }^{37}$ Furthermore, persons in the later stages of Alzheimer's will easily satisfy two of the MAiD eligibility conditions for having a "grievous and irremediable medical condition": they have "a serious and incurable illness" and by then they will be in "an advanced

\footnotetext{
${ }^{36}$ Aminoff and Adunsky 2004, 246. See also Mitchell, et al. 2009; Hendriks, et al. 2014.

${ }^{37}$ Alzheimer's has high heritability: Bertram and Tanzi 2012.
} 
state of irreversible decline in capability". ${ }^{38}$ For what it is worth, since Alzheimer's is invariably fatal they may also satisfy the condition that "their natural death has become reasonably foreseeable". As far as the remaining condition is concerned, determining whether/when the suffering of a late-stage Alzheimer's patient is "intolerable to them and ... cannot be relieved under conditions that they consider acceptable" is complicated by the patient's inability to communicate at that point. I will return to this issue later (sections 10-12). However, it is clear that, when viewed in advance from a position of capability, the symptoms of late-stage Alzheimer's will appear to many people as intolerable and to be avoided by whatever means are available. Once those symptoms are being experienced it will be too late to seek relief from them by requesting MAiD. The only route to this means of escape would be via an advance request, either before or after diagnosis.

Advanced dementia is not the only possible future condition of incapacity for which a person may wish to request MAiD: irreversible unconsciousness is another. A permanent vegetative state (PVS) is a condition in which all 'higher-brain' functions (those supported by the cerebrum and especially the cortex) have ceased while 'lower-brain' (and especially brainstem) functions are still intact. These differential outcomes can occur because the cerebrum is more sensitive than the brainstem to interruptions of circulation; a cutoff of oxygen supply to the brain of several minutes' duration might damage the cerebrum beyond repair while allowing the brainstem to resume functioning once circulation has been restored. PVS patients lack all capacity for cognitive functions, external awareness, and purposeful movement; however, they are usually capable of breathing on their own, without mechanical assistance, and can remain in this condition for many years as long as they are sustained by nutrition and hydration delivered through a feeding tube (since they are unable to swallow on their own).

It is now settled in Canadian law, as in most common law jurisdictions, that lifesustaining treatment, such as tube feeding, can be removed from a patient in a permanent

${ }^{38}$ Bill C-14, s. 241.2 (2). 
vegetative state, on the basis of a prior refusal of such treatment. ${ }^{39}$ The effect of such removal is that the patient will die of dehydration, usually within a period of 7-10 days. It would be entirely anomalous if it were possible for someone anticipating the possibility of PVS to elect a slow death by treatment refusal but not a quick one by a request for MAiD.

\section{MAiD and Dementia}

Earlier (section 4) I considered some of Rebecca Dresser's criticisms of reliance on advance directives for decision-making for incapacitated patients, concluding that they were not sufficient to undermine the value and function of such directives. Those criticisms - targeting deficits of information and specificity_applied across all scenarios of incapacity. However, Dresser has also made further points specific to directives that anticipate incapacity due to advanced dementia. To those I now turn.

Many of her contributions on this issue have been in response to some arguments of Ronald Dworkin. The context of these discussions was limited to patients with advance directives refusing life-sustaining treatment under stated conditions. But the arguments on both sides of the issue apply equally to advance requests for MAiD. The dialectic began with an example introduced and discussed by Dworkin:

When Andrew Firlik was a medical student, he met a fifty-four-year-old Alzheimer's victim whom he called Margo, and he began to visit her daily in her apartment, where she was cared for by an attendant. The apartment had many locks to keep Margo from slipping out at night and wandering in the park in a nightgown, which she had done before. Margo said she knew who Firlik was each time he arrived, but she never used his name, and he suspected that this was just politeness. She said she was reading mysteries, but Firlik "noticed that her place in the book jumps randomly from day to day; dozens of pages are dog-eared at any given moment....Maybe she feels good just sitting and

\footnotetext{
${ }^{39}$ Fleming v. Reid, (1991) CanLII 2728 (ON CA): http://canlii.ca/t/1p78q. Cf. Cruzan v. Director, Missouri Department of Health, (1990) 497 US 261; Airedale NHS Trust v. Bland, [1993] 1 All ER 821.
} 
humming to herself, rocking back and forth slowly, nodding off liberally, occasionally turning to a fresh page". Margo attended an art class for Alzheimer's victims- they all, including her, painted pretty much the same picture every time, except near the end, just before death, when the pictures became more primitive. Firlik was confused, he said, by the fact that "despite her illness, or maybe somehow because of it, Margo is undeniably one of the happiest people I have ever known." He reports, particularly, her pleasure at eating peanut-butter-and-jelly sandwiches. ${ }^{40}$

Dworkin invites us to imagine that years before, when she was fully competent, Margo gave considerable thought to the overall course of her life and reached the settled conviction that she never wanted to live as a demented person; perhaps she regarded such a life, however happy it might be, as undignified or demeaning. (If we wish, we can also imagine that Margo's negative assessment of such a life was informed by her experience of her mother's final years.) Acting on this conviction, she executed an instruction directive declining all life-sustaining treatment in the event that she should reach the advanced stages of Alzheimer's. Now she has acquired an infection easily treatable by antibiotics but fatal if left untreated. Should her earlier refusal of treatment be respected, allowing her to die despite the evident fact that she is now quite happy?

Dworkin contends that it should, on grounds of both Margo's autonomy and her wellbeing. He argues that, due to her dementia, Margo is no longer capable of making autonomous decisions about how her life should go. But she was once capable of such decisions-indeed, made just such a decision — and respect for her precedent autonomy requires doing now what she then directed. Thus far, we might seem to have another case of conflict between patient autonomy and patient interest: respect for Margo's prior autonomy will require us to do what is worse for her now, namely, allow her to die. But Dworkin resists this construal of the situation, arguing that honouring Margo's advance refusal may also be in her overall best interest.

\footnotetext{
${ }^{40}$ Dworkin 1993, 220-1, citing Firlik 1991.
} 
He supports this contention with a distinction between two types of interest, which he calls experiential and critical. Our experiential interests consist of the pleasure or enjoyment we take in things that we do or that happen to us. Margo has always had experiential interests and still does, since she gives every sign of enjoying her mystery book, her art class, and her peanutbutter-and-jelly sandwiches. Allowing her to die would be contrary to her current experiential interests. Critical interests, on the other hand, are based on a person's convictions of how their life should go and the goods it should contain. Margo's critical interests, Dworkin argues, were formed by her past convictions about the overall course of her life, including her wish not to finish it as a demented person. Margo is now unable to form critical interests, Dworkin claims, since she now lacks the capacity to think about the overall course of her life, but she retains the critical interests she formed while previously competent. Postponing her death by giving her life-sustaining treatment would be contrary to those interests. Since Dworkin considers that, in case of conflict, critical interests should be given priority over experiential interests, he concludes that, all things considered, honouring Margo's advance refusal would best serve her well-being (as well as her autonomy).

Before proceeding further, we should note some pretty distinctive features of Dworkin's Margo example. First, from Firlik's description it seems fairly clear that Margo has not yet reached late-stage Alzheimer's: though her memory seems clearly impaired, her language skills are still intact, she is able to feed herself, and she has the motor skills necessary for painting (as well as wandering in the park). Indeed, it is not even clear that Margo has entirely lost the capacity to make her own treatment decisions. This is important because, in Dworkin's imagining of the case, Margo's refusal of life-sustaining treatment is to kick in when she has reached the advanced stages of Alzheimer's. So it might be premature to be considering whether to act on her advance instructions. If Margo is indeed a late-stage Alzheimer's patient then she is a very atypical one, and conclusions about her case may not apply to the more typical cases. On the other hand, it might not matter that she is (atypically) happy, if (as Dworkin stipulates) her 
aim in executing the directive was not to avoid later suffering but just to avoid living as a demented person.

In any case, Dresser disagrees with Dworkin in two important respects. First, she argues that there are special problems with an advance refusal of treatment by a (formerly) competent person which, if respected, would be contrary to the best interest of the (later) incompetent patient. In such cases, she urges, the substitute decision-maker should attempt to make the treatment decision that is in the patient's best interest. ${ }^{41}$ Thus, she rejects Dworkin's contention that we are bound to respect Margo's (precedent) autonomy. Second, she argues that in applying the best interest standard only Margo's current experiential interests should be considered, in which case the decision should be made to prolong her life, at least as long as she continues to be happy. Clearly this second claim is crucial to her view, since if she were to acknowledge that Margo's critical interests are also in play, then the best interest standard she favours might entail complying with Margo's advance refusal of life-sustaining treatment. Dresser puts her point in the following way: "Happy and contented Margo will experience clear harm from the decision that purports to advance the critical interests she no longer cares about. This seems to me justification for a policy against... withholding effective, nonburdensome treatments, such as antibiotics, from dementia patients whose lives offer them the sorts of pleasures and satisfactions Margo enjoys." 42

The decision to withhold treatment will cause Margo "clear harm" only to her experiential interests. Why, then, are we not also to consider her critical interests? Dresser's answer to this question is - and must be - that these interests no longer matter because "she no longer cares about" them. She develops this point at greater length in a later discussion:

\footnotetext{
${ }^{41}$ Dresser 1986, 383ff; Dresser 2003, 1842-4. It is worth noting that, contrary to Dresser, under Canadian law a prior directive takes precedence over the patient's best interest. A substitute decision-maker is required to make decisions based on the patient's prior wishes, if they are known, and on the patient's best interest, only if their prior wishes are not known. (Expert Panel Working Group on Advance Requests for MAiD 2018, 92-5) For a critique of Dresser on this point, see Rhoden 1990.

${ }^{42}$ Dresser 1995, 36.
} 
If a patient can no longer appreciate the values that motivated the [advance] choice, treatment decisions should take into account what now matters to the patient. When the capacity to appreciate critical interests is lost, experiential interests should take priority. Competent persons are free to elevate their critical interests above experiential interests. But after they lose decisional capacity, they have a different set of concerns. Experiential interests become central to their lives. Experiential interests should also be central to decisions about their life-sustaining treatment. ${ }^{43}$

In other words: if you are no longer capable of caring about your critical interests then those interests no longer matter.

Dresser provides no real defence for this contention and it is difficult to see how it could be defended. In an influential discussion, Agnieska Jaworska takes issue with Dresser on this very point:

The fact that the demented patient no longer affirms critical interests in no way implies that he does not have critical interests. Since such interests are not inherently timespecific, the prudential importance of satisfying them may survive the person's unawareness of their satisfaction, whether due to unconsciousness, dementia, or even death. Thus, a demented person who cannot generate contemporaneous critical interests may still have some of the same critical interests he professed when he was healthy. ${ }^{44}$ It is easy to see Jaworska's point. If you once accept Dworkin's notion of critical interestswhich Dresser does - and if these interests include a person's settled conviction about how the end-stage of their life should go, what reason could there be for discounting these interests simply because the person has later lost the capacity to endorse, or even understand, them? It would be a different matter if, at some stage before or during the gradual onset of her dementia, Margo had reconsidered and disavowed her earlier disparagement of life in a demented condition. In that case there would be no reason to consider her earlier view of the matter still

\footnotetext{
${ }^{43}$ Dresser 2003, 1840 (footnotes omitted). Cf. Cohen-Almagor 2016, 81-2.

${ }^{44}$ Jaworska 1999, 111.
} 
authoritative as an expression either of her autonomy or of her interests. But we are to suppose that she neither rethought nor revoked her refusal of treatment when she was still capable of doing so. Now that she has lost this capacity (as we are to assume), her earlier directions remain our only evidence of where her current critical interests lie. Disregarding these interests because she has now lost the capacity to appreciate them would seem to undermine the whole point of advance care planning. If I execute an instruction directive while capable then my aim in doing so is to direct my care when I later become incapable. It would be perverse to disregard my earlier directive simply because I am now in the very condition of incapacity I anticipated in executing it in the first place.

Dresser, however, has one more card to play. The rationale behind advance care planning is based on the assumption that the (earlier) competent person who executes the directive is the same as the (later) incompetent person whose care it directs. However, this assumption is open to question. On the psychological view of personal identity, two person-stages belong to one and the same person if and only if enough relations of connectedness and continuity hold between their mental states (especially forward-looking connections such as intention and backwardlooking connections such as memory). ${ }^{45}$ However, it can be argued that in cases of severe dementia these connections fail to hold, since the later demented person is capable neither of carrying out any plans made by the earlier competent person nor of remembering anything about that person. In that case, according to the psychological view, we may be dealing, not with different stages of the same person, but with two different persons. Dresser then asks the obvious question: “...why should a patient who is now a different person be burdened by a treatment decision consistent with the former person's preferences? Compelling justification is lacking for according greater respect to the wishes of the earlier person (no longer in existence) than to the interests of the existing one." 46

\footnotetext{
${ }^{45}$ See, for instance, Parfit 1984, sec. 78.

${ }^{46}$ Dresser 1986, 381. Cf. Dresser 1989, 157ff. In a similar vein, see Walsh 2020.
} 
If we consider pre-demented Margo and now-demented Margo to be two different persons then there is surely no reason to think that decisions made by the former should have any authority over the latter. This case against advance care planning — what David DeGrazia has nicely labelled 'the someone else problem'- has been much discussed in the literature. ${ }^{47}$ This is not the place to summarize all of the argumentative moves that have been made to date, but I think it is pretty clear by now that the case has not been satisfactorily made out. ${ }^{48}$ For one thing, not everyone is persuaded that the psychological account of personal identity is correct, and at least some rival accounts will not support the conclusion that the two Margos are numerically distinct. ${ }^{49}$ It would seem foolhardy to let the fate of advance directives for dementia turn on the outcome of a contest between rival metaphysical theories. For another, even on the psychological view there may be enough continuity between the two Margos to consider them the same person, especially if the onset of dementia is slow and gradual. ${ }^{50}$ Finally, the implications that Dresser attempts to draw from the psychological account, if taken literally, are massively counterintuitive. ${ }^{51}$ Margo's daughter, who (let us say) is now her SDM, does not really doubt that this woman who is reading her book and enjoying her sandwiches is the same woman who was born in Vancouver in 1931, grew up in Montreal, married at the age of twentyseven, had three children, etc. If she is mistaken on this point, if this is not her mother, then why is she being accorded the status of substitute decision-maker, since she has no right to make such decisions on behalf of a stranger? Furthermore, why is this Margo still being treated as the legal owner of that property in Nova Scotia and these investment certificates? If the previous, competent Margo no longer exists, where did she go? Did she die? If so, why did no one notice? How did this Margo come into existence? And why is she even called Margo?

\footnotetext{
${ }^{47}$ Besides Dresser, see Buchanan and Brock 1989, ch. 3; Cantor 1993, ch. 6; Kuhse 1999; Olick 2001, ch. 4; DeGrazia 2005, ch. 5; Wrigley 2007; Asscher and van de Vathorst 2020.

${ }^{48}$ It is noteworthy that Dresser herself has come to make less and less use of this particular objection to advance directives, to the point where it has virtually disappeared by the time of Dresser 2003 .

${ }^{49}$ See, for instance, McMahan 2002, chs. $1 \&$ 5; DeGrazia 2005, chs. 2-5.

${ }^{50}$ Buchanan and Brock 1989, $159 \mathrm{ff}$.

${ }^{51}$ Cf. Rhoden 1990, 853-4.
} 
Philosophical theories of personal identity do not prevent families, friends, health care providers, hospitals, and courts from assuming continuity of identity between the previously competent person and the currently incapacitated one. Perhaps in this instance it is better to fit theory to practice rather than the other way around.

However this may be, the question remains: What should Margo's medical providers do? If her advance directive refused life-sustaining treatment should they now withhold antibiotics and allow her to die of her infection? Or if it requested MAiD should they now administer it? ${ }^{52}$ Or should they, in either case, ignore her directive and keep her alive to enjoy her peanut butterand-jelly sandwiches? Perhaps, like Dresser, we cannot imagine ourselves acting on either directive in the face of Margo's current contentment with her (diminished) life. Our reluctance to do so might just be perspectival error: we are confronted daily by Margo's current experiential enjoyments, whereas her previous disparagement of the life she is now living seems barely visible in the distant past. If we wish to give our reluctance some philosophical support then the obvious means would be to agree with Dresser in rejecting Dworkin's privileging of critical over experiential interests. As a general thesis, however, it is hard to see how one might argue that current pleasures and enjoyments, under conditions of diminished or nonexistent autonomy, always take precedence over previous, fully autonomous, expressions of one's deepest and most enduring values.

It is well to keep in mind that Margo is the easiest case for Dresser's rejection of advance directives and the hardest case for Dworkin's defence of them. Mid-stage Alzheimer's is seldom as rosy as Margo's day-to-day experience, and the end-stages of the disease never are. As noted earlier, as patients slide further and further into dementia it is far more common for their lives to be marked by increased suffering. In these cases current experiential interests no longer speak so unequivocally in favour of prolonging life, and the case for acting on an advance refusal/request becomes stronger. In order to dismiss reliance on advance directives altogether for patients with

\footnotetext{
${ }^{52}$ It might be thought that she could not now qualify for MAiD since she is not now suffering. For further exploration of this issue see sections 10-12, below.
} 
dementia, Dresser would have to contend that we could never have a sufficient reason for honouring a directive, however distressed the person had become. No such sweeping claim seems at all plausible.

\section{What Can We Learn from Other Jurisdictions?}

If we wish to gain a sense of how advance MAiD requests might work in practice, we need to look abroad. Worldwide, more than a dozen jurisdictions now make MAiD legally available (in one form or another), but only four (the Netherlands, Belgium, Luxembourg, and Colombia) make any provision for advance requests. In Belgium and Luxembourg MAiD can be administered, pursuant to an advance request, only in the case of irreversible unconsciousness (permanent vegetative state, or PVS), while little or no information is available concerning the disposition of advance MAiD requests in Colombia. Only in the Netherlands can MAiD be administered in cases of advanced dementia; therefore, virtually all of the information we have about the practice in that context comes from that jurisdiction.

MAiD became legal in the Netherlands under the Termination of Life on Request and Assisted Suicide (Review Procedures) Act of 2002. ${ }^{53}$ In order to conform to the 'due care criteria' specified in the Act a physician must:

a. be satisfied that the patient's request is voluntary and well-considered;

b. be satisfied that the patient's suffering is unbearable, with no prospect of improvement;

c. have informed the patient about his situation and prognosis;

d. have come to the conclusion, together with the patient, that there is no reasonable alternative in the patient's situation;

e. have consulted at least one other, independent physician, who must see the patient and give a written opinion on whether the due care criteria set out in (a) to (d) have been fulfilled;

${ }^{53} \mathrm{https} / / /$ www.ieb-eib.org/ancien-site/pdf/loi-euthanasie-pays-bas-en-eng.pdf. 
f. have exercised due medical care and attention in terminating the patient's life or assisting in his suicide. ${ }^{54}$

The Act includes a provision that written advance requests for MAiD can be prepared by anyone aged sixteen years or older. ${ }^{55}$ In the case of MAiD administered pursuant to an advance request, the due care criteria are to be followed "mutatis mutandis" (i.e., to the greatest extent possible in the given situation). ${ }^{56}$ However, although advance MAiD requests have been legally permitted in the Netherlands since 2002, very few have actually been implemented. One survey of physicians, many of whose elderly patients had registered advance requests, found that MAiD ended up being administered only rarely, and never in patients deemed to be incapable. ${ }^{57}$ More recently, a study of the annual reports of the Regional Euthanasia Review Committees from 2002 to 2017 found that "all or most of the patients who received euthanasia due to suffering caused by dementia were in the initial stages of the disorder and still had decisional capacity". ${ }^{58}$ Only sixteen cases fell outside this category, and of them only six concerned patients who (a) received MAiD as a result of a written advance request and (b) were registered by the Regional Review Committee as decisionally incapable..$^{59}$ Five of those six patients had Alzheimer's, while the sixth was simply recorded as suffering from dementia. Overall, the Review Committees found that the due care criteria had been complied with in all but four of the sixteen cases. These four cases were referred to the Public Prosecution Service. ${ }^{60}$

Two of these cases merit some attention for the issues they raise, not just for the application (mutatis mutandis) of the due care criteria, but more generally for any regime that

\footnotetext{
${ }^{54}$ Regional Euthanasia Review Committees 2018, 8. https://english.euthanasiecommissie.nl/thecommittees/documents/publications/euthanasia-code/euthanasia-code-2018/euthanasia-code2018/euthanasia-code-2018

${ }^{55}$ In the Netherlands these documents are known as advance euthanasia directives. However, in the interest of terminological uniformity I will continue to speak of advance MAiD requests.

${ }^{56}$ Ibid., 39.

${ }^{57}$ de Boer, et al. 2010.

${ }^{58}$ Expert Panel Working Group on Advance Requests for MAiD 2018, 122. See also Mevis, et al. 2016.

${ }^{59}$ Ibid., 127-9. In the other ten cases the patient's decisional capacity was found to be "questionable".

${ }^{60} \mathrm{https}: / / \mathrm{www}$. dutchnews.nl/news/2018/03/dutch-public-prosecutor-investigates-four-new-euthanasiacases/. Last accessed 25/05/20.
} 
would allow advance requests for MAiD to be implemented for patients with dementia who have lost decisional capacity.

\section{9. "Voluntary and Well-considered Request"}

The MAiD regime in the Netherlands attaches a great deal of importance to personal autonomy. It is therefore foundational that MAiD can be administered only in case of a fully voluntary and informed request by a decisionally capable patient. In normal circumstances this request is made at the time at which the procedure is to be carried out, or at least reaffirmed at that time. In the case of an advance request, however, the conditions of decisional capacity, voluntariness, and information must be satisfied at the time that the written request is drawn up. That instrument will stipulate a later condition of incapacity—such as advanced dementiaunder which the request for MAiD is to be implemented. This leaves open an awkward possibility: what is to be done if the later, incapacitated, person appears to decline or refuse what the earlier, competent person has requested?

Something like that scenario occurred in a recent case that made it all the way to the Dutch Supreme Court. ${ }^{61}$ The patient in the case is unnamed, but for ease of reference I am going to call her Ms. A. In September 2012, at the age of seventy, Ms. A was diagnosed with Alzheimer's. Shortly after receiving this diagnosis, she completed a written advance request in

\footnotetext{
${ }^{61}$ My information about this case is drawn from (English translations of three sources:

(1) Regional Euthanasia Review Committees 2016, 54-8: https://english.euthanasiecommissie.nl/the-committees/documents/publications/annualreports/2002/annual-reports/annual-reports;

(2) the decision of the District Court of the Hague (10 November 2019) [henceforth: District Court 2019]:

https://uitspraken.rechtspraak.nl/inziendocument?id=ECLI:NL:RBDHA:2019:10650\&showbutton=true\& keyword=euthanasia;

(3) the decision of the Dutch Supreme Court (21 April 2020) [henceforth: Supreme Court 2020]: https://uitspraken.rechtspraak.nl/inziendocument?id=ECLI:NL:PHR:2019:1338\&showbutton=true\&keyw ord=euthanasia.

The case has been much discussed in the bioethics and legal literature: see, for instance, Miller, Dresser and Kim 2019; Menzel 2019; Cohen-Almagor 2019; Asscher and van de Vathorst 2020; McMorrow 2021.
} 
which she stated that she wanted MAiD administered when she reached the point at which she was no longer able to live at home with her husband. She also signed a power of attorney for medical decision-making in which she appointed her husband as her substitute decision-maker, and her daughter as backup. In her written request she made it very clear that she did not want to be admitted to a nursing home. Her mother, who had died of Alzheimer's, had spent twelve years in such an institution, and Ms. A was adamant that she did not want this to happen to her. Her aunts, two brothers, and a sister had also all died of the same disease. In January 2015 she reaffirmed her wishes in a second written request. There is no doubt, based on the record, that on both occasions she was decisionally capable and her request met the condition of being voluntary and well-considered.

So far, her advance requests score well on grounds of voluntariness, information, and specificity. However, Ms. A also managed to cloud the issues a little. In her first directive she asked that MAiD be performed when she is "still to some degree decisionally competent" and in her second "when I myself think the time is ripe". In the latter she also stated: "I trust that, by the time the quality of my life has become so poor, euthanasia will be performed at my request." These phrases suggest that she expected to have some later role in deciding when the right time had come. However, the point of writing the advance request was to register her wishes, while decisionally capable, for a later time when she would have lost capacity. Once having lost capacity, she could not expect to be making a decision about when "the time is ripe". This evident confusion about the role of the advance request somewhat compromised it and, unsurprisingly, also complicated its later application. However, it was clear from the beginning that Ms. A's dominant wish was to be administered MAiD when she reached the stage of her dementia when she could no longer be cared for at home and had to be admitted to a nursing home.

Throughout the remainder of 2015, Ms. A's condition deteriorated significantly. She began to spend one day a week in the nursing home, in order to relieve the care burden on her husband, and then this gradually expanded to five days a week. Finally, in March 2016 she was 
admitted to the nursing home. Upon admission, Ms. A's husband discussed her advance MAiD request with the geriatric specialist who became responsible for her care. This specialist then initiated the process of determining whether the due care criteria for MAiD could be met in Ms. A's case. She consulted with Ms. A's general practitioner, her psychologist, her husband and daughter, a consultant from the 'end-of-life' clinic, and two physicians from SCEN (Support and Consultation for Euthanasia in the Netherlands): a psychiatrist and an internist. The geriatric specialist and the consultants all agreed that the due care criteria were met. In April 2016 the geriatric specialist administered MAiD to Ms. A, in the presence of her husband and daughter.

Upon review, the Regional Euthanasia Review Committee found that the due care criteria had not all been met and in 2016 referred the case to the Public Prosecution Service, which initiated a prosecution (the first such prosecution since the 2002 law came into effect). ${ }^{62}$ In November 2019 the decision of the District Court of the Hague disagreed with the Review Committee, finding that all of the due care criteria had been complied with. This decision was then affirmed in April 2020 by the Supreme Court.

There are important points of contention in this case that require much fuller discussion. But before turning to them, we can set aside two issues that are not contested. The first is that, by the time Ms. A entered the nursing home, she was severely demented and had become decisionally incapable. This was agreed by every physician that examined her during that time, including the SCEN psychiatrist who was qualified to decide issues of capacity. It was also agreed by the Review Committee and the courts. This is important, since her admission to the nursing home satisfied the condition for MAiD recorded in her advance request, and her current incapacity meant that the request could now be acted on (assuming that the due care criteria could be satisfied).

The second issue is that, during her time in the nursing home, Ms. A was suffering unbearably. Under normal circumstances, the way for a physician to determine whether, or

\footnotetext{
${ }^{62}$ In March 2019 the Central Disciplinary Board (the medical regulatory body) agreed with the Review Committee's finding and issued a warning to the specialist.
} 
when, the patient's suffering has become unbearable would be to ask the patient. But for severely demented patients like Ms. A this may not be possible, in which case other means of assessment will be necessary. The Regional Euthanasia Review Committees' Euthanasia Code states that: "The patient's consciousness of his suffering may be apparent from what he says, or from his other utterances or physical reactions. It is the overall picture that matters. In cases where a patient can no longer express his suffering in words, the physician must be alert to other signals that may reveal the patient's burden of suffering". ${ }^{63}$ The District Court summarized those "other signals" as follows:

It was observed that the patient during the larger part of the day showed signs of agitation, unrest, stress, anxiousness, sorrow, anger and panic. She cried a lot, often said that she found it horrible and that it was breaking her down and said every day (up to 20 times a day) that she wanted to die. Her day and night rhythm was disrupted and almost every day she wandered over the hallways, also at night. She banged on the windows and doors until her hands hurt. She accosted random people believing that they were acquaintances. This often led to physical conflicts with fellow residents. There was also a physical degradation of her person, by large dependency and incontinence. ${ }^{64}$

As we saw earlier, all of the foregoing symptoms are common in late-stage Alzheimer's. The Review Committee and the courts all agreed that the due care criterion of unbearable suffering was met in Ms. A's case.

What was at issue in the case was a seeming conflict between Ms. A's former wishes, as recorded in her advance requests, and her current wishes. Having reached the point of admission to the nursing home, Ms. A had lost the capacity to understand both her own condition and what MAiD is. However, when the latter was explained to her ("You will get a needle and then not wake up") she would say something like "No, I don't want that" or "Maybe later, but not now".

\footnotetext{
${ }^{63}$ Regional Euthanasia Review Committees 2018, 22. Cf. Expert Panel Working Group on Advance Requests for MAiD 2018, 52-3.

${ }^{64}$ District Court 2019, at para 5.3.3.
} 
In principle, the 2002 law allows an advance written request for MAiD to substitute for a current oral request. But can it so substitute if the patient is now not only not saying "yes" but is actually saying "no"? In a situation like this, which is to take precedence: the patient's prior capable request or her current incapable refusal? That is the fundamental issue that the Review Committee and the courts had to contend with (and about which they disagreed).

We are a long way from Dworkin's Margo here, since by no stretch of the imagination was Ms. A happy and contented once in the nursing home. Nor is it a conflict between critical and experiential interests, since all of Ms. A's interests point in the same direction. Instead, it is more like a clash of wills: the current incapacitated will v. the prior capable one. The conflict was not made easier to resolve by Ms. A's inclusion in her written requests of phrases like "when I myself think the time is ripe" or "at my request", as though she was expecting to have final signoff on MAiD.

When MAiD was finally administered, Ms. A clearly had no understanding of what was happening. In order to sedate her, the geriatric specialist dissolved midazolam in her coffee, because Ms. A was not taking any medication and would probably have refused to take the midazolam herself. When it became clear that the sedative was not having a sufficient effect, a second dose was administered with a syringe. Once Ms. A was unconscious, a cannula was inserted. However, when the physician tried to administer the thiopental, Ms. A sat up. Her family then held her and the physician quickly administered the remaining medication.

In light of the wording of Ms. A's advance request, the Review Committee considered that "doubt persists as to whether the patient wanted the advance directive to take the place of an oral request" and therefore concluded: "In the absence of an oral request from the patient asking the physician to actually perform euthanasia and the absence of a clear advance directive to replace such a request, ... the physician could not have concluded unequivocally that she had made a voluntary and well-considered request for euthanasia". ${ }^{65}$ In that case the due care

\footnotetext{
${ }^{65}$ Regional Euthanasia Review Committees 2016, 58.
} 
criterion had not been met.

The District Court attached more weight to Ms. A's subsequent incapacity and concluded that at that stage "she was ... no longer able to communicate her own will in a coherent way". Therefore:

It is the opinion of the court that, in view of the state of profound dementia the patient was in, the accused did not have the obligation to obtain information from the patient about her present wish to live or to die. This is a requirement, which is not laid down in the law. The specific situation of the incapacitated patient leads to the fact that an oral verification of his wish to live and his suffering is impossible. Setting this requirement would be detrimental to the living will of the patient, which is specifically intended for the situation in which the person who drafted the living will ends up in a state of unbearable and hopeless suffering and is no longer able to express his will. ${ }^{66}$ The District Court's judgement was referred to the Supreme Court for the purpose of gaining some clarity about the state of the law. Contrary to the Review Committee, the Supreme Court interpreted Ms. A's advance requests as implying that "the patient wanted to hand over control of the moment of euthanasia to a doctor upon admission" to the nursing home. "With another interpretation, namely that the patient only wanted euthanasia as long as she could still determine that moment herself, her written advance directive would lose all meaning..."67 The court then agreed with the lower court's decision:

The court is of the opinion that, given the deeply demented condition in which the patient was now, the [physician] was not obliged to inquire about a current life or death wish of the patient. This sets a requirement that the law does not know. The specific position of the incapacitated patient means that oral verification of his wish and his suffering is not possible. That requirement would undermine the living will, which is precisely intended

\footnotetext{
${ }^{66}$ District Court 2019, at para 5.3.2. [emphasis in original].

${ }^{67}$ Supreme Court 2020, at para 8.16.
} 
for the situation where the person who has issued the living will enters a situation of unbearable and hopeless suffering and is no longer able to express his will. ${ }^{68}$

The most important aspect of this decision for our purposes is its declaration that a person incapacitated by profound dementia is "no longer able to express his will" and that therefore "oral verification of his wish...is not possible" ${ }^{69}$ In that case, present incapable wishes to live or die have no weight against prior capable ones. The effect of the Supreme Court's decision has therefore been to strengthen the authority of advance MAiD requests in the Netherlands, by determining that they can stand as a "voluntary and well-considered" request at the appropriate later time, in the absence of a wish to die, or even in the presence of a wish to live, at that later time. In light of this decision, the Euthanasia Code of the Regional Euthanasia Review Committees has since been amended to state that, where a patient has advanced dementia, "it is not necessary for the doctor to agree with the patient the time or manner in which euthanasia will be given". ${ }^{70}$

This clarification of the "voluntary and well-considered request" condition will not suffice by itself to justify administering MAiD to an incapacitated patient, since the other due care criteria also have to be satisfied. To the most important of those further criteria I now turn.

\footnotetext{
${ }^{68} \mathrm{Ibid}$., at para 10.3. [emphasis in original]

${ }^{69}$ This key finding was disputed in an opinion piece in the Dutch newspaper de Volkskrant (5 May 2020), written by two clinicians and a lawyer: https://www.volkskrant.nl/columns-opinie/opinie-uitgangspunthoge-raad-dat-iemand-met-voortgeschreden-dementie-geen-wil-heeft-niet-houdbaar b 744ab87/. Agnieszka Jaworska has argued that at least some Alzheimer's patients are capable of both having and, to a lesser extent, acting on values, and that this capacity for valuing is all that is necessary in order to have both critical interests (in Dworkin's sense) and a rudimentary form of autonomy. (Jaworska 1999) However, Jaworska is here referring to early- to mid-stage dementia patients (such as Margo), not to patients as deeply demented as Ms. A.

${ }^{70}$ Daniel Boffey, "Dutch euthanasia rules changed after acquittal in sedative case", The Guardian, 20 November 2020. https://www.theguardian.com/world/2020/nov/20/dutch-euthanasia-rules-changed-afteracquittal-in-sedative-case. Last accessed 24/11/20. For a dissenting view of this case, and the one discussed in the next section, see Klaas Rozemond, "Euthanasia with demented elderly can be done much better at an early stage", www.nrc.n1/nieuws/2020/08/31. Last accessed 24/11/20.
} 


\section{0. "Unbearable Suffering"}

In addition to patient autonomy, exemplified by the requirement of a voluntary and wellconsidered request, the Dutch system places a great deal of emphasis on patient suffering. The due care criteria require that the patient's suffering, at the time at which MAiD is to be administered, must be "unbearable, with no prospect of improvement". As noted earlier, in the case of a capable patient the normal means of determining when suffering has become unbearable is to consult the patient. As the Regional Euthanasia Review Committees put it: It is sometimes hard to establish whether suffering is unbearable, for this is a subjective notion. What is bearable for one patient may be unbearable for another. This depends on the individual patient's perception of his situation, his life history and medical history, personality, values and physical and mental stamina. It must be palpable to the physician, also in light of what has happened so far, that this particular patient's suffering is unbearable. The physician must therefore not only be able to empathise with the patient's situation, but also see it from the patient's point of view. ${ }^{71}$

This criterion of unbearable suffering is also meant to be applied mutatis mutandis to patients with advanced dementia. But how is this meant to work with patients who no longer have a "point of view" on their own suffering, or with whom communication on this issue has become impossible? In the survey of Dutch physicians, cited earlier, the main impediment mentioned by the respondents to administering MAiD to deeply demented patients was the impossibility of communicating with these patients, thus the difficulty of determining whether their suffering was unbearable. ${ }^{72}$ As we saw earlier in the case of Ms. A, the Review Committees state that "in cases where a patient can no longer express his suffering in words, the physician must be alert to other signals that may reveal the patient's burden of suffering" ${ }^{73}$

Where Ms. A was concerned, those "other signals" led all of the doctors involved in her case, the

\footnotetext{
${ }^{71}$ Regional Euthanasia Review Committees 2018, 24.

${ }^{72}$ de Boer, et al. 2010.

${ }^{73}$ Regional Euthanasia Review Committees 2018, 22.
} 
Review Committee that examined it, and both of the courts to agree that her suffering was indeed unbearable. But what is to be done if there are no such signals?

This problem was central to the case of a woman I will call Ms. B. ${ }^{74}$ On three occasions from 1992 to 1994 (well in advance of the euthanasia law), Ms. B signed advance requests for MAiD to be administered in the event of early dementia, dependence on others, or permanent admission to a nursing home. Unlike the advance request of Ms. A, these documents were not complicated by any suggestion that she expected to have a say in the matter if/when any of these conditions were satisfied. Ms. B also appointed both of her children as her substitute decisionmakers. In 2012 she suffered a stroke but recovered quickly and was able to return home. At that time she was informed by her general practitioner that admission to a nursing home might be necessary in case of a second stroke. Six months later she suffered a second stroke, which left her with aphasia, cognitive impairment, mobility problems, and seizures. She was then admitted to a nursing home. Since her condition was considered incurable, treatment in the nursing home was palliative only. Subsequent to her admission, her children asked a physician from the endof-life clinic to administer MAiD, pursuant to Ms. B's advance request. In August 2012 the physician did so. Ms. B was eighty to ninety years old at the time.

Two things are clear in this case. The first is that Ms. B was fully decisionally capable in 1992 to 1994 when she wrote her advance MAiD requests. Although she never subsequently updated or rewrote them, she did discuss the issue on a number of occasions with her general practitioner. Her children also confirmed that her request remained current prior to her second stroke. The second is that Ms. B was decisionally incapable following the second stroke, when her aphasia and cognitive impairment made communication with her impossible. Since, unlike the case of Ms. A, there was no evidence that Ms. B had changed her mind on the matter, the

\footnotetext{
${ }^{74} \mathrm{My}$ information about this case is based on the report of the Regional Euthanasia Review Committee: https://www.euthanasiecommissie.nl/uitspraken/publicaties/oordelen/2014/vrijwillig-enweloverwogen/oordeel-2014-02.
} 
Review Committee that examined the case concluded that her advance request constituted a voluntary and well-considered request for MAiD, satisfying that due care criterion.

That left the issue of unbearable suffering. Once in the nursing home, Ms. B was utterly unable to express verbally whether she was suffering and, if so, whether she found her suffering unbearable. However, unlike the case of Ms. A, the "other signals that may reveal the patient's burden of suffering" were also largely absent. Though Ms. B was subject to mood swings, and could occasionally be aggressive, in general she was calm and friendly. The consultant who was called in on the case claimed to find signs of despair, frustration, and desolation in Ms. B's eyes, and reported that the patient had clearly indicated, both verbally and non-verbally, that she did not want to be in her current situation. The Review Committee, however, was unconvinced that these indications were sufficient to establish unbearable suffering.

By contrast, the physician from the end-of-life clinic, who administered MAiD, claimed not to observe any signs of occurrent suffering in Ms. B. Instead, he took the view that Ms. B's unbearable suffering consisted in the fact that she now found herself in the very situationpermanent admission to a nursing home - that she had indicated in her advance request would be intolerable to her. Here then was the crucial issue: were the terms of that advance request sufficient to conclude that Ms. B was now suffering unbearably, or did there now need to be additional behavioural evidence of her suffering? The Review Committee's ruling was that "the mere fact that the patient has had to leave her own environment permanently and was admitted to a nursing home is insufficient to assume the agony of her suffering", despite the terms of her advance request. The Committee therefore found that the due care criterion of unbearable suffering had not been met. The case was referred to the Public Prosecution Service, but, as far as I have been able to ascertain, no prosecution was subsequently initiated.

\section{Two Lessons from the Netherlands}

Ms. A was found to be suffering unbearably at the time at which MAiD was administered, but in light of some of her current statements the question was whether her 
advance directive still stood as a voluntary and well-considered request. Ms. B's advance request was found to be still perfectly valid, with no contraindications, but in light of her current condition the question was whether she was now suffering. The two cases between them put pressure on the Netherlands' two most important criteria of due care. ${ }^{75}$ So what lessons might we take away from them for a possible regime in Canada?

To simplify matters, I will assume that we are dealing with a case of a decisionally capable patient who has made a voluntary and fully informed advance request that MAiD be administered under carefully specified conditions in the event of later incapacity due to profound dementia, and that those conditions now obtain. ${ }^{76}$ The Dutch cases raise important questions both about the current authority of the advance consent and about the requirement that the patient now be suffering. I will consider these in turn.

Consent. The Dutch courts (but not the Review Committee) found that Ms. A's expressions of a wish to live, or not to die yet, could be disregarded since, in her profound dementia, she was "no longer capable of expressing her will". By that they seem to have meant that, because at this point she was no longer capable of understanding what administering MAiD would mean, she was therefore incapable of revoking or overriding her prior request for it. This raises a very important question. As we saw earlier, valid consent to treatment presupposes (among other conditions) a voluntary and fully informed decision by a capable subject. In their decisions in this case, the Dutch courts have effectively imposed these same validity conditions on refusal of treatment. Because Ms. A was incapacitated and could not be informed about MAiD, and because she could not "express her will", her 'refusal' (if that is what it was) was of no force and

\footnotetext{
${ }^{75}$ The two other substantive criteria effectively become moot when applied mutatis mutandis to profoundly demented patients. In those cases the physician will be unable to "inform the patient about his situation and prognosis" or "come to the conclusion, together with the patient, that there is no reasonable alternative in the patient's situation". It will then be sufficient for the physician to determine that the patient's prognosis is indeed hopeless and that there is no reasonable alternative to MAiD. ${ }^{76}$ I mean to include here both requests made post-diagnosis of dementia but pre-approval for MAiD (like Ms. A) and requests made pre-diagnosis (like Ms. B). As long as they are equally voluntary and informed, I see no significant difference between them. I return to this issue later (section 12).
} 
effect. The courts have therefore effectively treated consent and refusal symmetrically, with the same validity conditions in both cases. But were they right to do so?

It is certainly possible to see why the courts took this position. In their eyes, they were protecting the integrity of advance requests made by decisionally capable persons: requiring the physician to inquire about the current wishes of the later deeply demented person "would undermine the living will, which is precisely intended for the situation where the person who has issued the living will ... is no longer able to express his will." And the courts have a point, if (as I argued earlier) the main purpose of advance requests for MAiD_-indeed of advance directives in general and of the whole edifice of informed consent - is to ensure the effective exercise of patient autonomy over personal health care decisions. If I autonomously specify the conditions under which I wish MAiD to be administered in the event of my later incapacity due to late-stage dementia, and I now find myself in those conditions, then my autonomous will is being thwarted if my request is not implemented. To refuse to proceed because my later demented self says that I don't (yet) want to die is not to favour my present autonomy over my prior autonomy, because I now have no autonomy. Instead, as the courts have put it, it has the effect of undermining the whole rationale for allowing advance requests in the first place.

The same issue of consent was central to a Canadian case, where, however, it concerned not MAiD but SED by AD. ${ }^{77}$ In 1991 Margot Bentley executed an advance directive that stated: "If at such a time the situation should arise that there is no reasonable expectation of my recovery from extreme physical or mental disability, I direct that I be allowed to die and not be kept alive by artificial means or heroic measures". She also listed specific instructions, including "no nourishment or liquids" and designated her husband and daughter as her SDMs. In 1999, Ms. Bentley was diagnosed with Alzheimer's disease and by 2005 her condition had deteriorated to the point that she needed to be moved to a residential care facility. In 2013, she was diagnosed with stage seven Alzheimer's (severe dementia). By that point she no longer recognized nor

\footnotetext{
${ }^{77}$ Bentley 2014; Bentley v. Maplewood Seniors Care Society 2015 BCCA 91 [henceforth Bentley 2015]; Pope and Richards 2015; Hammond 2016.
} 
responded to her family and had lost all verbal abilities and basic motor skills. Her days were spent either motionless in bed or slumped in a wheelchair with her eyes closed. To survive, she required spoon-feeding by care-givers. The staff at the care facility assisted her with eating and drinking by placing a spoon or glass on her lower lip. When she opened her mouth to accept food or fluids, the care attendant placed it in her mouth and Ms. Bentley swallowed it. When she kept her mouth closed despite being prompted, the care attendant would try again. If she continued to keep her mouth closed despite a couple of attempts, the care attendant would make no attempt to force her to accept either food or fluids.

Ms. Bentley's family wanted to honour her advance directive and therefore requested that the care facility stop providing her with food and fluids. When the facility refused to do so, Ms. Bentley's husband and daughter petitioned the Supreme Court of British Columbia for declaratory relief that would prohibit the facility from providing Ms. Bentley with oral nutrition and hydration. In its 2014 decision the Court denied that relief. As in the case of Ms. A, it found some ambiguities in Ms. Bentley's advance directive: specifically, whether she meant to refuse oral feeding, as a matter of personal care, rather than administration of nutrition and hydration as a part of health care. But more importantly, and somewhat surprisingly, it ruled that Ms. Bentley's sometimes acceptance of food and fluids, by opening her mouth and swallowing, constituted valid consent to assisted feeding, despite her severely demented condition. Relying on this finding of fact by the trial judge, in 2015 the British Columbia Court of Appeal upheld the lower court decision. Ms. Bentley remained in the care facility, where she died in November 2016.

The parallels between Ms. A and Ms. Bentley are clear, despite the fact that the former was (at least apparently) registering an advance request for MAiD in the event of incapacity, while the latter was (at least apparently) registering an advance refusal of oral feeding in the 
event of incapacity. ${ }^{78}$ Both women eventually reached a stage of severe dementia and both were, by all reasonable standards, decisionally incapable. At that stage each woman was displaying behaviour that could be construed as overriding their prior, pre-dementia wishes: Ms. A by rejecting MAiD and Ms. Bentley by accepting oral feeding. The question in each case was whether the behaviour in question constituted valid refusal/consent. The Dutch courts ruled that Ms. A's 'refusal' was invalid, seemingly because it failed to live up to the normal standards for valid consent, while the Canadian courts reached the opposite conclusion about Ms. Bentley's 'consent', despite the fact that it too fell well short of those standards. ${ }^{79}$ The Dutch courts privileged Ms. A's earlier competent wishes over her later incompetent behaviour, while the Canadian courts did the opposite.

Suffering. The Dutch criterion of unbearable suffering finds its echo in the Canadian law that requires a patient to have "a serious and incurable illness, disease or disability ... that causes them enduring physical or psychological suffering that is intolerable to them and that cannot be relieved under conditions that they consider acceptable". ${ }^{0}$ The question raised by the case of Ms. B is how to adapt that condition to accommodate advance requests in anticipation of severe dementia. What the Dutch have effectively done is to keep the suffering criterion in place, by requiring evidence of current distress on the part of the demented patient. While this may make sense in the context of the Dutch MAiD legislation, it does result in serious anomalies.

In order to satisfy the due care criterion of unbearable suffering, the patient must retain some level of consciousness; in the Netherlands, therefore, unlike Belgium, MAiD cannot be administered to patients in a permanent vegetative state. ${ }^{81}$ But this exclusion seems arbitrary and

\footnotetext{
${ }^{78}$ Here I gloss over the ambiguities in the two written directives in order to focus on the issue of consent/refusal. However, one clear message from the two cases is the necessity of a clearly formulated advance request or refusal. I return to this issue in section 12, below.

${ }^{79}$ As one commentator put it, the court applied "a remarkably low test for decisional capacity". (Pope and Richards 2015, 390; see also Pope 2019). To gain a sense of just how low the test was, compare Ms. Bentley's level of functioning to the standard criteria for determining capacity: Appelbaum 2007, 1836. ${ }^{80}$ Bill C-14, s. 241.2(2)(a)(c).

${ }^{81}$ Regional Euthanasia Review Committees 2018, 21. From 2002 to 2017 there were 322 cases of advance MAiD directives being acted on for PVS patients in Belgium. (Ibid., 111)
} 
indefensible. Implementing advance MAiD requests for PVS patients is a much simpler matter than it is for dementia patients, since the former have no possibility of indicating dissent and no occurrent experiential interests that could serve as a contraindication. Once a jurisdiction is willing to take the step of allowing advance requests in anticipation of severe dementia, it would be perverse of it not to do the same for permanent unconsciousness.

Since a PVS patient is incapable of suffering, a requirement of current intolerable suffering is not a good fit for all cases of advance MAiD requests. It should be sufficient in those cases that the state that the patient is currently in is the very one for which they requested MAiD in an advance directive. But then the same point can be made for dementia cases. Suppose, like Dworkin's Margo, that what you are attempting to avoid, by writing your advance MAiD request, is not later suffering while demented but just being in a demented condition. It is easy, I think, to understand how some people (not everyone) could consider such a condition intolerable, as an affront to their dignity. Requiring them additionally to be suffering while in that condition would, once again, thwart their autonomous will.

The two lessons from the Netherlands have a common theme: How much authority should be given to (capable) advance requests over later (incapable) behaviour, whether the latter consists in declarations of a wish to live or the complete absence of experiential suffering?

\section{Advance Requests for MAiD: Practicalities}

Since there is a strong ethical case in favour of advance requests, there is also a strong incentive to find a way of accommodating them within the existing legislative framework for MAiD in Canada. In order to see how this might be done, it will be helpful to return to the doctrine of informed consent (section 1). To borrow a phrase from the Dutch, its four conditions for valid consent to treatment will have to be adapted, mutatis mutandis, to accommodate advance requests.

Capacity. Questions of capacity will arise at two junctures: the time of the initial request and the time of its potential implementation. At both junctures advance MAiD requests introduce no 
issues not already encountered for other advance directives, especially those that refuse lifesustaining medical treatment, or personal care, in the event of incapacity. This does not mean, however, that no safeguards are called for. Advance directives of all kinds are meant to be drawn up while the person still has capacity. Decisional capacity for an advance MAiD request is quite specific: it is the ability to make a reasoned decision concerning this treatment under these later conditions. In most cases determining capacity at the time of request will be straightforward, but there may sometimes be room for doubt, especially where the person is already in the early stages of dementia. In cases of doubt, recourse can be had either to one of the widely used scales for tracking the progressive stages of dementia ${ }^{82}$, or to a specialist who is qualified to determine capacity.

An advance request for MAiD will stipulate the conditions under which it is to be implemented (more on this below). But implementation cannot occur until the patient has reached a state of incapacity. For many patients in late-stage Alzheimer's there may be little doubt that this state has been reached. But it is important to have certainty. The same scales mentioned above will, of course, serve here as well, but it may also be worthwhile to borrow a practice from the Dutch, where incapacity can be determined only by an appropriately qualified independent specialist consulting on the case. This specialist could also serve as the second practitioner required by the MAiD law to determine that the criteria for MAiD have been satisfied.

Doubts about capacity may arise as well in cases of loss of consciousness. 'PVS' is often, perhaps usually, taken to be the abbreviation of persistent vegetative state. But the condition is designated 'persistent' when it has lasted for one month after initial brain damage, and 'permanent' when it has lasted for at least a year and is considered irreversible. ${ }^{83}$ Because

\footnotetext{
${ }^{82}$ Two such scales: the Functional Assessment Staging Test (FAST) and the Global Deterioration Scale (GDS): https://www.mccare.com/pdf/fast.pdf; https://www.dementiacarecentral.com/aboutdementia/facts/stages/ (last accessed 07/03/21). For an overview of capacity assessment, see Appelbaum 2007.

${ }^{83}$ Laureys 2005; Laureys 2007.
} 
disorders of consciousness can be challenging to diagnose with certainty, in this case as well it would be appropriate to seek an opinion from a qualified specialist that the patient's loss of consciousness - and therefore of capacity — is indeed permanent and irreversible. ${ }^{84}$

In the case of both conditions, if there is reasonable doubt about loss of capacity then implementation of the advance request must not go forward.

Consent. Explicit consent for MAiD will be given by the advance request itself. In the case of advance refusals of life-sustaining treatment, there is often room for doubt in determining precisely which treatment modalities the person has expressed a wish to decline (this was very much a factor in the case of Margot Bentley). However, where MAiD is concerned this should not be a problem, since the procedure being requested is quite specific. That should settle the question of what is being requested. However, it is also crucial that the request be specific about when it is to be implemented, i.e., the conditions under which MAiD is to be administered. Any uncertainty or ambiguity on this issue will leave both providers and SDMs (and possibly courts as well) in an unenviable position.

The importance of clarity on this point became clear in the case of Ms A. Her advance request stipulated that she wished MAiD to be administered when her dementia had reached the stage where she needed to be admitted to a nursing home. While that threshold was clearly defined, and seemed to be based on the assumption that by that point she would have lost capacity, Ms. A also asked that MAiD be performed when she is "still to some degree decisionally competent" and "when I myself think the time is ripe", suggesting that even after admission to the nursing home she expected to retain at least some degree of decisional capacity. The seeming contradiction in her advance request concerning the implementation conditions for MAiD was one of the factors that made her case so complicated.

A person writing an advance request in anticipation of PVS will have no difficulty in defining their personal threshold: MAiD is to be administered once unconsciousness has been

\footnotetext{
${ }^{84}$ Unless the patient has stipulated in their advance request that they wish MAiD to be administered in the event of unconsciousness for a specified period (such as a year). I owe this point to Jocelyn Downie.
} 
diagnosed as permanent. Progressive dementia, however, is a much messier affair, and here it becomes important to stipulate implementation conditions as fully as possible, so that both providers and SDMs will be able to determine when the threshold has been crossed. Everyone gets to define their own limits, but they need to define them clearly. That threshold might come when the patient is no longer able to consistently recognize close family members, when they have become permanently bedridden or incontinent, when they have begun to experience frequent bouts of crying or rage or violence, when they can no longer speak in sentences, when they are suffering from pain or shortness of breath, or any combination of the foregoing. One option available in defining a threshold is to utilize one of the objective scales of disease progression: one might say, for instance, "When I reach Stage 7 on the FAST Scale" ${ }^{85}$ It would also be useful for health care organizations, advocacy groups, or the government to provide model advance request documents, in which the necessary information would be solicited. ${ }^{86}$ Persons contemplating executing an advance request may also benefit from counselling or professional assistance. It is equally important that the person appointed as proxy be fully briefed on the conditions of life that have been determined in advance to be intolerable. The task of writing an advance request that will offer clear guidance to providers and SDMs is not a simple one. But it is certainly not more difficult, and is in some respects easier, than providing similarly clear guidance for the withholding or withdrawal of life-sustaining treatment.

It is a standard feature of advance care planning that, having once given consent to treatment, a capable person may withdraw that consent at any time. Where PVS is concerned, this cannot happen after onset of the condition. But once again dementia cases may be much more fraught. What are we to do in cases like that of Ms. A, where the patient has continually reaffirmed their advance MAiD request while capable, only to show signs of refusal of, or

\footnotetext{
${ }^{85}$ See n. 82 , above.

${ }^{86}$ Such models already exist for advance refusals of treatment; see, e.g., https://static1.squarespace.com/static/5a0128cf8fd4d22ca11 a 405d/t/5f9202eee 780d71b5005366d/160340 $4559093 /$ dementia-directive.pdf. Last accessed $06 / 03 / 21$. They could be readily adapted to advance requests for MAiD.
} 
resistance to, the procedure when incapable? As we saw earlier, the Dutch courts have taken the position that the validity conditions for later refusal are the same as those for earlier consent, so that refusal of previously requested treatment by an incapable person need not be an obstacle to administering it, while the Canadian courts have adopted a remarkably low bar for valid consent to feeding for someone who has written an advance directive refusing food and water. So far at least, the Canadian government appears to be taking the latter approach. The limited provision for advance MAiD requests in Bill C-7 includes the stipulation that "the person does not demonstrate, by words, sounds, or gestures, refusal to have [MAiD] administered or resistance to its administration". 87

If this same stipulation were to be applied to expanded provisions for advance requests, then the remaining question would be whether persons determined not to have their precedent autonomy thwarted by their own later demented selves might be able to write their advance request as a 'Ulysses pact', ${ }^{88}$ under whose terms MAiD is to be administered in the event of incapacity even in the face of refusal or resistance.

Voluntariness. As in the case of contemporaneous consent, the patient's giving of advance consent to MAiD must be free of undue influence and coercion, whether by providers or by family or friends. Special attention may need to be paid to persons with disabilities, in order to ensure that their advance request/refusal is not made in anticipation of lack of appropriate care following loss of capacity. But it would be invidious to assume that having a disability, even a serious one, necessarily renders a person incapable of making fully voluntary end-of-life decisions. $^{89}$

\footnotetext{
${ }^{87}$ Bill C-7, s. 241.2(3.2)(c). S. (3.3) adds the following: "For greater certainty, involuntary words, sounds or gestures made in response to contact do not constitute a demonstration of refusal or resistance for the purposes of paragraph (3.2)(c)."

${ }^{88}$ The term refers to the story of Ulysses (Odysseus) in Homer's Odyssey, who wished to hear the Sirens' song, though he knew that doing so would drive him temporarily mad. He stopped his men's ears with wax and ordered them to bind him to the mast and to disobey any later orders to set him free or to sail toward the Sirens. It is now the general term for a contract or agreement meant to bind later decisionmaking.

${ }^{89}$ See Sumner 2018.
} 
Information. Along with vagueness or ambiguity, deficits of information are one of the main problems that critics find with advance directives. However, there is no reason to think that advance requests for MAiD will be particularly susceptible to this problem. The nature and prospects of PVS are well understood, while Alzheimer's is a well-known and highly publicized disorder, with a well-defined progression of symptoms from early to late stage. The timing will vary with individuals, the disease progressing more quickly with some than others, but not the nature of its assault. Thus it is reasonable to expect an advance MAiD request with Alzheimer's in mind to be well informed about what life will be like in the later stages of the disease. Furthermore, because the disease progresses gradually, rather than in sudden onslaughts, a patient will also have a good deal of time to reconsider and (if a change of heart occurs) revoke the request, before losing the capacity to do so. ${ }^{90}$

An advance request is especially likely to be well informed if it is drawn up after diagnosis with dementia. That brings us to an important issue. As noted at the outset, advance MAiD requests are often sorted into three categories: (a) after approval for MAiD but before administration, (b) after diagnosis of a "grievous and irremediable medical condition" but prior to approval, and (c) prior to diagnosis. ${ }^{91}$ The terms of Bill C-7 allow requests of type (a), but only for patients whose natural death is "reasonably foreseeable". That leaves types (b) and (c), and the question whether there is a significant difference between them.

This question has an analogue in another of the residual issues that the 2016 MAiD law left for future consideration: whether MAiD should be accessible to 'mature minors'. The current law restricts access to persons 18 years of age and over. That age limit was presumably chosen because it was thought to be an indicator of maturity, thus of decisional capacity for endof-life decision-making. If so, it is far from reliable. Some 16- and 17-year-olds will have the capacity to request MAiD for their medical condition and some 18- and 19-year-olds will lack it.

\footnotetext{
${ }^{90}$ The situation will be different for cases of incapacity resulting from sudden events, such as stroke or traumatic brain injury.

${ }^{91}$ Expert Panel Working Group on Advance Requests for MAiD 2018, ch. 4.
} 
What matters directly is capacity, with chronological age figuring only as a rough and imperfect measure of it, in which case we should go directly to what matters and use capacity and not age as an eligibility criterion for MAiD.${ }^{92}$ Doing so would complicate the approval process for MAiD, since it would require capacity assessments for mature minors. But to exclude otherwise eligible patients just because they have not yet celebrated their eighteenth birthday would be arbitrary and discriminatory (especially in light of the fact that mature minors already have the right to refuse life-sustaining treatment).

So too in the present case. Diagnosis of "a serious and incurable illness, disease or disability" is a very significant event which is likely to concentrate any patient's mind on their end-of-life care. But it is only a rough and imperfect indicator of what really matters in this case, which is informedness. With diagnosis will come specific information not only about the disease in question but, more importantly, about the nature and timing of its likely future course with this patient. So, other things equal, advance MAiD requests post-diagnosis are likely to be better informed than requests pre-diagnosis. But other things are not always equal, and requests before diagnosis can be very well informed indeed. Ms. A's advance request was made shortly after her diagnosis of Alzheimer's, but she was already well informed not only about the disease but also about her risk of falling prey to it. Her mother had spent twelve years in an institution wasting away with Alzheimer's, and the disease had already claimed her aunts and three of her siblings. Ms. A knew a lot about Alzheimer's before she was diagnosed with it. Had her advance request been made before diagnosis it would not have been significantly less informed. Ms. B's advance request was registered decades before her first stroke, but it too did not suffer from informational deficits. Like chronological age for mature minors, time of diagnosis is just a surrogate for what really matters. In that case, we should focus directly on ensuring that advance requests are

\footnotetext{
${ }^{92}$ There is some precedent for this approach in Belgium. (Sumner 2017, 80)
} 
adequately informed and not enforce an arbitrary distinction between those made pre- and postdiagnosis. ${ }^{93}$

The focus on time of diagnosis can also point to something else that is important in its own right: the elapsed time between the request and realization of the conditions for its implementation. As we saw earlier, one of the worries about advance directives in general is that they can become obsolete, either because new factual information has become available or because the patient's own values have changed. In order to avoid this problem it would seem a good idea to borrow another practice from Belgium, where advance MAiD requests are required by law to be updated every five years and to be included in the patient's medical record. Implementing this measure may require creating provincial registries for advance requests (currently only Quebec has such a registry), but that is a good idea in its own right. The updating requirement would have the effect not only of ensuring that patients remain well informed about the relevant medical facts but also of giving them an opportunity to rethink their own values and preferences.

I conclude that there is good reason to think that the standard conditions for informed consent to treatment can be successfully adapted to advance requests for MAiD. There is, however, one other issue of adaptation to be addressed. Like the Dutch criteria of due care, the statutory eligibility criteria for MAiD will also have to be applied, mutatis mutandis, to the special circumstances of advance requests. In the terms of the legislation as enacted in June 2016:

(2) A person has a grievous and irremediable medical condition only if they meet all of the following criteria:

(a) they have a serious and incurable illness, disease or disability;

(b) they are in an advanced state of irreversible decline in capability;

\footnotetext{
${ }^{93}$ In any case, advance MAiD requests in anticipation of PVS must necessarily be drawn up prediagnosis.
} 
(c) that illness, disease or disability or that state of decline causes them enduring physical or psychological suffering that is intolerable to them and that cannot be relieved under conditions that they consider acceptable; and

(d) their natural death has become reasonably foreseeable, taking into account all of their medical circumstances, without a prognosis necessarily having been made as to the specific length of time that they have remaining. ${ }^{94}$

Patients with advanced dementia, or in a permanent vegetative state, easily qualify as having "a serious and incurable illness" and being "in an advanced state of irreversible decline in capability". The amendments in Bill C-7 partially removed the condition that "natural death has become reasonably foreseeable". ${ }^{95}$ This leaves us with the condition of intolerable suffering.

Earlier we saw the difficulties the Dutch have encountered in applying their comparable due care criterion in the case of severely demented patients who are unable to communicate whether they find their suffering unbearable. But we also saw that there is a deeper problem with the suffering criterion: it cannot be satisfied in the case of patients in a permanent vegetative state. Since it would be absurd to allow requests for MAiD to be implemented for demented patients but not for irreversibly unconscious ones, the whole issue needs to be rethought. The current Canadian criterion of intolerable suffering, which has its place for contemporaneous decision-making, cannot just be automatically copied forward for at least some cases of advance requests.

So how to fix this? At least three options are available:

1. We could retain the criterion for dementia cases and apply it (as the Dutch do) by relying on "other signals that may reveal the patient's burden of suffering", while dropping it for PVS cases,

\footnotetext{
${ }^{94} \mathrm{C}-14$, s. $241.2(2)$.

${ }^{95}$ But only partially. Under the terms of C-7, patients requesting MAiD will be placed on one of two tracks, depending on whether they satisfy this condition. Those whose natural death is deemed to be reasonably foreseeable will have access to a fast track that includes elimination of the mandatory 10-day waiting period imposed by the 2016 legislation and the possibility of registering an advance request (but only at the time of approval for MAiD). Those who do not satisfy the condition can now be eligible for MAiD, but only under additional procedural safeguards, including a mandatory 90 -day interval between assessment and administration, and with no possibility of advance requests.
} 
where it is inapplicable. This may give us the right answers for both categories of cases, but it seems annoyingly ad hoc.

2. We could drop the criterion for all cases of advance requests while retaining it for contemporaneous requests. For patients incapacitated by either PVS or dementia, the mere fact that they now find themselves in the condition specified in their advance request would suffice for implementing the request, without any requirement of occurrent suffering.

3. We could retain the criterion for all advance requests while interpreting it as being satisfied when the patient finds themselves in the condition (whether it be PVS or advanced dementia) specified in their advance request. This was the position adopted by the physician who administered MAiD to Ms. B.

Options 2 and 3 would be similar in practice and either would be a good fit for PVS cases. As between them, the third has the advantage of seeming less ad hoc, since intolerable suffering would remain an eligibility criterion for all cases in a revised MAiD law, though with a distinctive interpretation for advance requests. However, for dementia patients both of these options would mean that MAiD could be administered, pursuant to the patient's advance request, in the complete absence of any signals of occurrent suffering, or even if the patient seems, or indeed is, like Dworkin's Margo, happy and contented.

PVS cases create difficulties not just for the "intolerable suffering" criterion but for the "reasonably foreseeable natural death" condition as well. If we are to allow advance MAiD requests to be implemented in such cases (as we should), then this condition will have to be waived. PVS patients can continue to live in their condition for years, as long as artificial hydration and nutrition are sustained. ${ }^{96}$ In such cases the patient's natural death could not be deemed to be reasonably foreseeable. But in this case the fix is easy. This condition for access to MAiD has suffered from the start from both ineliminable vagueness and lack of an evident

\footnotetext{
${ }^{96}$ Nancy Cruzan, the central figure in the landmark U.S. case concerning the withdrawal of life-sustaining treatment from a PVS patient, lapsed into her condition in 1983 and died in 1990 when her feeding tube was removed.
} 
rationale. ${ }^{97}$ It is time to go beyond the half-hearted reforms of Bill C-7 and abolish the requirement entirely, for advance requests and for contemporaneous decision-making as well.

\section{Conclusions}

To recapitulate: It is universally recognized that informed consent to treatment is an indispensable device for protecting both patient autonomy and patient well-being. Advance care planning, including the use of advance directives, is its logical extension over time, allowing persons, while capable, to direct their care in the event of later incapacity. Advance directives enable persons to elect, or refuse, treatment while incapacitated. Advance requests for MAiD are a special case of advance directives, requesting a particular treatment under specified conditions. The goals and values served by informed consent are equally served by advance treatment directives, including advance MAiD requests. In particular, there is no ethical difference between advance MAiD requests and at least some advance directives refusing life-sustaining treatment.

The only remaining question, therefore, is practical: how to integrate advance MAiD requests into Canada's existing regime for MAiD. In the foregoing I have urged five changes to the current MAiD legislation, each of them more extensive than the limited amendments in Bill C-7:

- The legislation must be further amended to allow for advance requests for MAiD, including requests made in anticipation of incapacity due either to permanent unconsciousness or to advanced dementia.

- $\quad$ The amendment must not distinguish between requests made before and after diagnosis of "a grievous and irremediable medical condition".

${ }^{97}$ Truchon v. Attorney General of Canada, 2019 QCCS 3792 (CanLII), http://canlii.ca/t/j2bzl. The difficulties inherent in interpreting the "reasonable foreseeability" condition are thoroughly explored in McMorrow, et al. 2020. 
- The amendment will need to modify the current requirement of intolerable suffering so as to allow MAiD to be administered to persons in a state of permanent unconsciousness. In so doing it must also clarify what constitutes intolerable suffering for persons with advanced dementia.

- The amendment will also need to clarify whether any sign of resistance to, or refusal of, MAiD by an incapacitated person negates that person's prior competent request for MAiD.

- The requirement that the patient's natural death be "reasonably foreseeable" must be entirely eliminated.

Ideally, the terms and conditions of revised legislation should be neither under- nor overinclusive. They would be under-inclusive if they arbitrarily disallowed entire categories of cases, such as patients in a permanent vegetative state or those whose requests were drawn up prior to diagnosis. These faults are easily avoided or corrected. They would be over-inclusive if they were susceptible to abuse or misapplication. These problems will arise either at the front end, when the request is drawn up, or the back end, when it is to be implemented. At various points I have suggested best practices and safeguards designed to protect against both abuses and mistakes: careful specification of the circumstances under which the request is to be implemented, competency assessments where either capacity or incapacity is subject to doubt, consultation with specialists in the disease condition in question, the development of model request forms, and registration and periodic renewal of written requests to ensure that they remain up to date. Better minds than mine will doubtless be able to come up with other ideas.

However carefully it is crafted, a legal regime that incorporates advance MAiD requests can be expected to yield hard cases, in which it will simply be unclear whether MAiD should or should not be administered. Anyone who doubts this should reread sections 8-11, above, tracking the experience of the Netherlands. Hard cases can be minimized by carefully drawn eligibility criteria and procedural safeguards, but they cannot be eliminated. The only way to eliminate them is to prohibit advance MAiD requests entirely. Absolute prohibitions of this sort 
are the lazy person's solution to the problem of hard cases. In this instance, such a prohibition would sacrifice all of the benefits of advance MAiD requests in the vast majority of easy cases in order to avoid the burdens of difficult decisions in the small minority of hard cases. For what it is worth, the Canadian courts have shown themselves reluctant to endorse blanket prohibitions, finding that they tend to suffer from the fatal flaw of over-breadth. This was the primary basis of the Supreme Court's decision in Carter to strike down the absolute prohibition of MAiD in favour of a more nuanced and selective approach with appropriate safeguards. ${ }^{98}$ It is important not to make the same mistake where advance MAiD requests are concerned. The inevitable minority of hard cases will be best dealt with, not by trying to prevent them from occurring in the first place, but by dealing with them on a case-by-case basis, bringing to bear the considerable resources provided by substitute decision-makers, assessors, and providers. If all else fails (it shouldn't), the courts will always be there as backup.

In pursuit of the goal of avoiding hard cases, or preventing abuses or mistakes, we must be careful not to erect such high fences around advance requests for MAiD that only a fortunate few will be able to surmount them (this would be under-inclusion again). In this matter, as in so many, we need to find the balance between minimizing risk and ensuring effective access. That is the continuing theme in Canadian MAiD legislation, which remains a work in progress. Bill C-14 was a first step, going no farther than required by the Carter decision (and in some respects not as far). The amendments in Bill C-7 constituted a small second step. However, as the government recognizes, there are further issues to confront and further changes that will need to be made. The accommodation of advance requests is one of them.

${ }^{98}$ Carter 2015, at paras 114-121. 


\section{Acknowledgements}

I am grateful to Raphael Cohen-Almagor, Jocelyn Downie, Cheryl Misak, Tom McMorrow, Kent McNeil, and Marleen Rozemond for their very helpful comments on various iterations of this piece.

\section{Bibliography}

Appelbaum, Paul S. 2007. "Assessment of Patients' Competence to Consent to Treatment." New England Journal of Medicine 357, no. 18.

Asscher, Eva Constance Alida, and Suzanne van de Vathorst. 2020. "First Prosecution of a Dutch Doctor Since the Euthanasia Act of 2002: What Does the Verdict Mean?" Journal of Medical Ethics 46.

Bernat, J.L., B. Gert, and R.P. Mogielnicki. 1993. "Patient Refusal of Hydration and Nutrition-an Alternative to Physician-Assisted Suicide or Voluntary Active Euthanasia." Archives of Internal Medicine 153, no. 24.

Bertram, Lars, and Rudolph E. Tanzi. 2012. "The Genetics of Alzheimer's Disease.” In Molecular Biology of Neurodegenerative Diseases, David B. Teplow. London: Academic Press.

Buchanan, Allen, and Dan W. Brock. 1989. Deciding for Others. Cambridge: Cambridge University Press.

Burns, Alistair, and Steve Iliffe. 2009. “Alzheimer's Disease.” British Medical Journal 338, no. 7692 .

Cantor, Norman L. 1993. Advance Directives and the Pursuit of Death with Dignity. Bloomington: Indiana University Press.

Cohen-Almagor, Raphael. 2016. "First Do No Harm: Euthanasia of Patients with Dementia in Belgium." Journal of Medicine and Philosophy 41, no. 1.

-----. 2019. "The Role of the Patient's Family, Surrogate and Guardian at the End of Life." European Journal for Person Centered Healthcare 7, no. 3. 
de Boer, Marike E., Rose-Marie Droes, Cees Jonker, Jan A. Eefsting, and Cees M.P.M. Hertogh. 2010. “Advance Directives for Euthanasia in Dementia: Do Law-Based Opportunities Lead to More Euthanasia?" Health Policy 98, no. 2-3.

DeGrazia, David. 2005. Human Identity and Bioethics. Cambridge: Cambridge University Press. Downie, Jocelyn. 2018. "An Alternative to Medical Assistance in Dying? The Legal Status of Voluntary Stopping Eating and Drinking (VSED)." Canadian Journal of Bioethics 1, no. 2.

Downie, Jocelyn, and Matthew J. Bowes. 2019. "Refusing Care as a Legal Pathway to Medical Assistance in Dying." Canadian Journal of Bioethics 2, no. 2.

Dresser, Rebecca. 1986. "Life, Death, and Incompetent Patients: Conceptual Infirmities and Hidden Values in the Law." Arizona Law Review 28, no. 3.

-----. 1989. “Advance Directives, Self-Determination, and Personal Identity.” In Advance Directives in Medicine, edited by Chris Hackler, Ray Moseley, and Dorothy E. Vawter. New York: Praeger.

------. 1994. “Advance Directives: Implications for Policy.” Hastings Center Report 24, no. 6.

------. 1995. “Dworkin on Dementia: Elegant Theory, Questionable Policy.” Hastings Center Report 25, no. 6 .

-----. 2003. "Precommitment: A Misguided Strategy for Securing Death with Dignity." Texas Law Review 81, no. 7.

Dworkin, Ronald. 1993. Life 's Dominion: An Argument About Abortion, Euthanasia, and Individual Freedom. New York: Random House, Inc.

Expert Panel Working Group on Advance Requests for MAiD. 2018. The State of Knowledge on Advance Requests for Medical Assistance in Dying. Ottawa: Council of Canadian Academies.

Faden, Ruth R., and Tom L. Beauchamp. 1986. A History and Theory of Informed Consent. New York: Oxford University Press.

Firlik, Andrew D. 1991. "Margo's Logo.” Journal of the American Medical Association 265, no. 2 . 
Gilmour, Joan. 2017. "Legal Capacity and Decision-Making." In Canadian Health Law and Policy (5th Ed.), edited by Joanna N. Erdman, Vanessa Gruben, and Erin Nelson. Toronto: LexisNexis Canada.

Hammond, Katherine. 2016. "Kept Alive: The Enduring Tragedy of Margot Bentley." Narrative Inquiry in Bioethics 6, no. 2.

Hendriks, Simone A., Martin Smalbrugge, Cees M.P.M. Hertogh, and Jenny T. van der Steen. 2014. "Dying with Dementia: Symptoms, Treatment, and Quality of Life in the Last Week of Life." Journal of Symptom and Pain Management 47, no. 4.

Jaworska, Agnieszka. 1999. "Respecting the Margins of Agency: Alzheimer's Patients and the Capacity to Value." Philosophy \& Public Affairs 28, no. 2.

Kuhse, Helga. 1999. "Some Reflections on the Problem of Advance Directives, Personhood, and Personal Identity." Kennedy Institute of Ethics Journal 9, no. 4.

Laureys, Steven. 2005. "Death, Unconsciousness and the Brain." Nature Reviews Neuroscience 6, no. 11.

-----. 2007. "Eyes Open, Brain Shut." Scientific American 296, no. 5.

Li, Madeline, and Danielle Kain. 2018. "The Other Side of Sorrow: Physician Reflections on Assisted Dying." Canadian Medical Association Journal 190, no. 6.

Li, Madeline, Sarah Watt, Marnie Escaf, Michael Gardam, Ann Heesters, Gerald O'Leary, and Gary Rodin. 2017. "Medical Assistance in Dying: Implementing a Hospital-Based Program in Canada." New England Journal of Medicine 376, no. 21.

Mader, Sarah, and Victoria Apold. 2019. "VSED as an Alternative to MAiD: A Pan-Canadian Legal Analysis.” doi:http://dx.doi.org/10.2139/ssrn.3500173.

McMahan, Jeff. 2002. The Ethics of Killing: Problems at the Margins of Life. Oxford: Oxford University Press.

McMorrow, Thomas. 2021. "The Waxing and Waning of Informed Consent: Medical Assistance in Dying and the Question of Advance Requests." Osgoode Hall Law Journal. 
McMorrow, Thomas, Ellen Wiebe, Ruchi Liyanage, Sabrina Tremblay-Huet, and Michaela Kelly. 2020. "Interpreting Eligibility Under the Medical Assistance in Dying Law: The Experiences of Physicians and Nurse Practitioners." McGill Journal of Law and Health 14, no. 1 .

Menzel, Paul T. 2017. "Voluntarily Stopping Eating and Drinking: A Normative Comparison with Refusing Lifesaving Treatment and Advance Directives." Journal of Law, Medicine, and Ethics 45, no. 4.

-----. 2019. “AEDs Are Problematic, but Mrs A is a Misleading Case." Journal of Medical Ethics 45, no. 2.

Menzel, Paul T., and M. Colette Chandler-Cramer. 2014. "Advance Directives, Dementia, and Withholding Food and Water by Mouth." Hastings Center Report 44, no. 3.

Mevis, Paul, Liselotte Postma, Michelle Habets, Judith Rietjens, and Agness van der Heide. 2016. “Advance Directives Requesting Euthanasia in the Netherlands: Do They Enable Euthanasia for Patients Who Lack Mental Capacity?" Journal of Medical Law and Ethics 4, no. 2 .

Miller, David Gibbes, Rebecca Dresser, and Scott Y.H. Kim. 2019. "Advance Euthanasia Directives: A Controversial Case and Its Ethical Implications." Journal of Medical Ethics 45, no. 2.

Mitchell, Susan L., Joan M. Teno, Dan K. Kiely, Michele L. Shaffer, Richard N. Jones, Holly G. Prigerson, Ladislav Volicer, Jane L. Givens, and Mary Beth Hamel. 2009. "The Clinical Course of Advanced Dementia." New England Journal of Medicine 361, no. 16.

Olick, Robert S. 2001. Taking Advance Directives Seriously. Washington: Georgetown University Press.

Parfit, Derek. 1984. Reasons and Persons. Oxford: Oxford University Press.

Pope, Thaddeus Mason. 2019. "Whether, When, and How to Honor Advance VSED Requests for End-Stage Dementia Patients." American Journal of Bioethics 19, no. 1. 
Pope, Thaddeus Mason, and Bernadette J. Richards. 2015. "Decision-Making: At the End of Life and the Provision of Pretreatment Advice." Journal of Bioethical Inquiry 12.

Provincial-Territorial Advisory Group on Physician-Assisted Dying. 2015. Final Report. Toronto: Provincial-Territorial Expert Advisory Group on Physician-Assisted Dying.

Quill, Timothy E., Paul T. Menzel, Thaddeus M. Pope, and Judith K. Schwartz, eds. 2021. Voluntarily Stopping Eating and Drinking: A Compassionate, Widely Available Option for Hastening Death. Oxford: Oxford University Press.

Regional Euthanasia Review Committees. 2016. Annual Report 2016.

-----. 2018. Euthanasia Code 2018: Review Procedures in Practice.

Rhoden, Nancy K. 1990. "The Limits of Legal Objectivity.” North Carolina Law Review 68, no. 5 .

Special Joint Committee on Physician-Assisted Dying. 2016. Report of the Special Joint Committee on Physician-Assisted Dying. Ottawa: Parliament of Canada.

Sumner, L.W. 2011. Assisted Death: A Study in Ethics and Law. Oxford: Oxford University Press.

-----. 2017. Physician-Assisted Death: What Everyone Needs to Know. New York: Oxford University Press.

-----. 2018. "Death, Disability, and Self-Determination." In From Disability Theory to Practice: Essays in Honor of Jerome E. Bickenbach, edited by Christopher Riddle. Lanham: Lexington Books.

Terman, Stanley A. 2007. The Best Way to Say Goodbye: A Legal Peaceful Choice at the End of Life. Carlsbad, CA: Life Transitions Publications.

Walsh, Emily. 2020. "Cognitive Transformation, Dementia, and the Moral Weight of Advance Directives." American Journal of Bioethics 20, no. 8.

Wrigley, Anthony. 2007. "Personal Identity, Autonomy and Advance Statements." Journal of Applied Philosophy 24, no. 4. 